\title{
Sub-basalt Imaging of Hydrocarbon-Bearing Mesozoic Sediments Using Ray-Trace Inversion of First-Arrival Seismic Data and Elastic Finite-Difference Full-Wave Modeling Along Sinor- Valod Profile of Deccan Syneclise, India
}

\author{
KARABI TALUKDAR ${ }^{1}$ and LAXMIDHAR BEHERA ${ }^{1}$
}

\begin{abstract}
Imaging below the basalt for hydrocarbon exploration is a global problem because of poor penetration and significant loss of seismic energy due to scattering, attenuation, absorption and mode-conversion when the seismic waves encounter a highly heterogeneous and rugose basalt layer. The conventional (short offset) seismic data acquisition, processing and modeling techniques adopted by the oil industry generally fails to image hydrocarbon-bearing sub-trappean Mesozoic sediments hidden below the basalt and is considered as a serious problem for hydrocarbon exploration in the world. To overcome this difficulty of sub-basalt imaging, we have generated dense synthetic seismic data with the help of elastic finite-difference full-wave modeling using staggered-grid scheme for the model derived from ray-trace inversion using sparse wide-angle seismic data acquired along Sinor-Valod profile in the Deccan Volcanic Province of India. The full-wave synthetic seismic data generated have been processed and imaged using conventional seismic data processing technique with Kirchhoff pre-stack time and depth migrations. The seismic image obtained correlates with all the structural features of the model obtained through ray-trace inversion of wide-angle seismic data, validating the effectiveness of robust elastic finite-difference full-wave modeling approach for imaging below thick basalts. Using the full-wave modeling also allows us to decipher smallscale heterogeneities imposed in the model as a measure of the rugose basalt interfaces, which could not be dealt with ray-trace inversion. Furthermore, we were able to accurately image thin lowvelocity hydrocarbon-bearing Mesozoic sediments sandwiched between and hidden below two thick sequences of high-velocity basalt layers lying above the basement.
\end{abstract}

Key words: Hydrocarbon, basalt, Mesozoic sediments, imaging, ray-trace inversion, elastic finite-difference, full-wave modeling.
1 CSIR-National Geophysical Research Institute (CSIRNGRI), Uppal Road, Hyderabad 500007, India. E-mail: laxmidhar@ngri.res.in

\section{Introduction}

The Deccan Volcanic Province (DVP) of India is an important large igneous province in the world, as it marks the Cretaceous-Paleocene ( $\sim 65 \mathrm{Ma}$ ) boundary, which has witnessed a major global climate change (Courtillot et al. 1988; Keller et al. 2008). When the Indian Plate was stationed over the Reunion hotspot and subsequently drifted northward away (during $\sim 65 \mathrm{Ma}$ ago) from it, there was extensive outpouring of basaltic lavas (predominantly tholeiitic), which resulted in the formation of the Deccan flood basalt volcanic province of India (Morgan 1972; Cox 1983; Devey and Lightfoot 1986; Mitchell and Widdowson 1991). It is considered that requisite heat generation due to Deccan volcanism soon after the Cretaceous (Mesozoic) sedimentation may have acted as a catalyst for the generation of hydrocarbon and accumulation below the basaltic trap forming a large hydrocarbon reservoir.

Sub-basalt imaging for hydrocarbon exploration is a challenging problem for the oil industry all over the world and particularly in India due to the presence of a thick Deccan trap. Basalts mainly act as a mask for the hydrocarbon-bearing Mesozoic sediments hidden below the Deccan trap-covered region of India called Deccan Syneclise (Murty et al. 2010). Due to large impedance contrasts at sediment-basalt interfaces and presence of breccias or vesicles within the lava flows, the primary reflections are masked by coherent noises such as groundrolls, multiples, diffractions, scattering and mode-conversions (Jarchow et al. 1994). The seismic data quality also degraded due to absorption and attenuation of elastic waves within the rugose basalt interfaces, which leads to poor 
penetration and severe loss of seismic energy, hence decrease in signal-to-noise ratio (SNR) in the nearvertical range. To overcome these types of problems, several studies have been made for imaging below the basalts using long-offset/wide-angle seismic data (Jarchow et al. 1994; Fliedner and White 2001, 2003; Fruehn et al. 2001; White et al. 2003; Behera and Sen 2014). The present study emphasizes how to image thin low-velocity Mesozoic sediments entrapped by thick columns of high-velocity basalts in the Deccan Syneclise region of India (Fig. 1) along the N-S trending Sinor-Valod seismic profile in which refraction and wide-angle seismic reflection data have been analyzed using the robust tomographic inversion technique (Behera and Sen 2014). The tomographic inversion technique as advocated by Zelt (1999) takes into account fine grid parameterizations seeking a smooth or minimum-structure velocity model, using the minimum number of prominent phases in the data, and little or no a priori information. This approach is designed to yield a model that only contains structure required by the most certain data as opposed to structure that is merely consistent with the data. This type of tomography can be applied in perhaps the most objective way possible for a given set of wide-angle traveltime data, i.e., using no a priori information and only a few parameters for which the values, within a somewhat predictable range, which do not greatly affect the final velocity model. This approach has been used for obtaining the minimum-structure velocity model using first-arrival traveltime tomography of wide-angle seismic data acquired in the Deccan trap-covered region of India (Behera and Sen 2014). The tomographic imaging for the first time has clearly brought out a smooth and minimum-structure velocity model along the 90-km-long wide-angle seismic profile in this highly complex Deccan trap with a meaningful interpretation of the presence and extension of sub-trappean Mesozoic sediments favorable for hydrocarbon accumulation, hidden below the thick and highly heterogeneous basalts (Behera and Sen 2014). However, refraction and wide-angle seismic reflection methods can accurately measure the velocity contrasts below the basalt but cannot resolve subtle layers hidden below the basalt or lying within the thick column of sediments or
Figure 1

Geology map of the Deccan Syneclise region of India (marked as key map in the inset) showing the N-S trending Sinor-Valod deep seismic profile (black line) with acquired wide-angle shots (SP1, SP2 as red dots) for sub-basalt imaging along with location of well near Ankleswar drilled by the ONGC. The different rock types exposed on the surface are indicated in the legend. The elevation of the study region is shown in the color scale with top panel represents the elevation along the profile of study (modified after Behera and Sen 2014)

image rugose basalt interfaces. On the other hand, short-offset seismic data have high-frequency information, which can resolve fine-scale structures if the energy can penetrate below the thick basalts. This is very useful to understand the internal structures within and below the basalt layers, but practically it never happens due to severe loss and poor penetration of seismic energy at top of the basalt layer. To overcome difficulties associated with sub-basalt imaging and accelerate hydrocarbon exploration activities in the Deccan Volcanic Province of India, we have adopted a robust elastic finite-difference full-wave modeling approach using staggered-grid scheme (Virieux 1986). This approach is capable of computing synthetic seismic data (shot gathers) using numerical simulation of elastic wave propagation through different layers having thick rugose basalts and thin hydrocarbon-bearing sub-trappean Mesozoic sediments in the Deccan trap-covered region of India as imaged by Behera and Sen (2014) with the help of robust tomographic inversion technique. Our study using elastic full-wave modeling, processing and imaging of synthetic seismic data generated over the same profile with close shot point intervals provide a better understanding of the study region with a more comprehensive and geologically plausible seismic image taking into consideration the tomographic velocity model as input.

The key to successful imaging below basalt is to understand how the seismic waves propagate through it at different times for a given seismic source. Since basalt is highly heterogeneous, a significant amount of incident seismic energy is attenuated, converted and scattered while propagating through the basalt layer, hence the seismic image quality becomes very poor. Therefore, it is necessary to develop proper seismic data acquisition and processing techniques to deal with different type of waves generated at the 

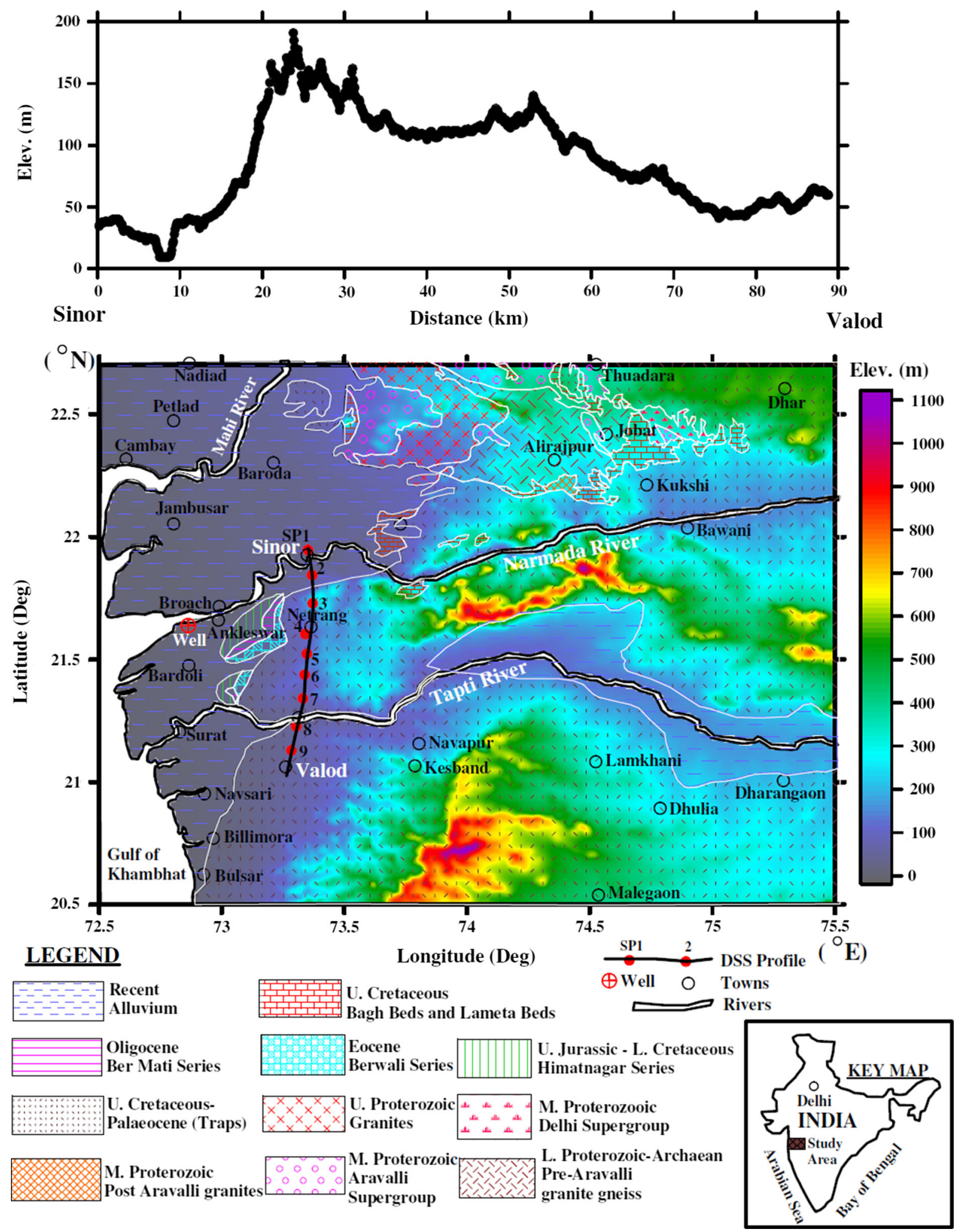
basalt interface (direct arrivals, primary reflections, multiples, mode-conversions, diffractions, groundrolls, scattering, etc.) using numerical simulation of elastic wave propagation through the model and generation of full-wave synthetic seismic data for sub-basalt imaging of Mesozoic sediments.

\section{Geology and Tectonics}

The Deccan Syneclise region of India has complex geology and tectonic settings with wide-spread lava flows (basalts) forming the Deccan trap (Fig. 1). The different rocks exposed on the surface are Archaean-Neoproterozoic granite gneiss and PalaeoMesoproterozoic Delhi/Aravalli supergroup in the north, Vindhyan sediments in the east and Cambay sedimentary basin lies in the western part of the study region. This region is also topographically highly undulated surrounded by deep valleys and hillocks confined by three major rivers called Narmada, Tapti and Mahi flowing from east to west and confluence in the Arabian Sea. The Deccan basalts were also encountered at different depths below the Tertiary sediments ranging in age from the Palaeocene to Recent confirmed from the well drilled in the Cambay basin (Roy 1991; Tewari et al. 1995; Dixit et al. 2010). The hydrocarbon-bearing Mesozoic sediments hidden below the Deccan trap, which correspond to upper Jurassic to middle Cretaceous Bagh and Lameta beds/formations are exposed toward east of Sinor in the Cambay basin (Fig. 1). The presence of sporadic outcrops of Jurassic and Cretaceous sediments on the margins of the Cambay basin leads to the possibility of a thicker sequence of marine sediments deposited within the basin below the Deccan trap. Most of the geological features and rock types are hidden below the different basaltic lava flows (traps) and pose a major challenge for hydrocarbon exploration in this region by the oil industries. The Deccan trap is a thick sequence of flat lying flood basalt flows covering nearly $500,000 \mathrm{~km}^{2}$ of westcentral India (Mahoney et al. 1989), associated with the Reunion hotspot representing a 2-km-thick succession (in Western Ghats) of lava flow (Beane et al. 1986). The center of the volcanic eruption lied near the west coast of India before the breakup of India and Seychelles that occurred $65 \mathrm{Ma}$ ago with major, rapid and short duration eruptive phases that lead to the formation of the Western Ghats, which might have lasted for 1.0-0.5 Ma (Courtillot et al. 1988; Duncan and Pyle 1988) with a report of very shortlived intense volcanism at the Cretaceous-Tertiary (K-T) boundary (Allègre et al. 1999). The whole province might have covered more than $1.5 \times 10^{6}$ $\mathrm{km}^{2}$ (Courtillot et al. 1986) of basalt with inclusion of correlative lava flows in the offshore (Arabian Sea). Several evidences indicate that most of the basaltic lavas were erupted rapidly. Recent ${ }^{40} \mathrm{Ar}-{ }^{39} \mathrm{Ar}$ incremental heating ages show that the Deccan volcanism has occurred within 65-69 Ma and the 2-km-thick Western Ghats section was erupted in less than $2 \mathrm{Ma}$ (Duncan and Pyle 1988). Taking into consideration all the evidences for duration of volcanism, most of the Deccan basalts may have accumulated in as little as $0.5 \mathrm{Ma}$. Based on this estimate, the average eruption rate could have been $1 \mathrm{~km}^{3}$ year $^{-1}$ with several episodes of eruptions separated by inactive periods (unconformities) with total duration of the volcanism was confined within 3 Ma (Kono 1973).

\section{Data and Methodology}

\subsection{Wide-Angle Seismic Data Along Sinor-Valod Profile}

The wide-angle seismic data allow application of a variety of analysis and imaging techniques that help overcome some of the problems faced by conventional seismic reflection profiling. Since reflection amplitudes generally increase with offset, sub-basalt reflections are more easily identifiable at wide-angle than narrow-angle ranges. Wide-angle arrivals are also less affected by multiples from the overburden as a consequence of the increasing difference in traveltime and moveout between the different phases. To image sub-trappean Mesozoic sediments and basement configuration, wide-angle seismic data have been acquired by NGRI during 2001-2003 along the 90-km-long Sinor-Valod seismic profile (Fig. 1) with shot point (SP) interval of $\sim 10 \mathrm{~km}$ and geophone group interval of $\sim 100 \mathrm{~m}$ having 10 geophones in a group (channel) with natural frequency of $10 \mathrm{~Hz}$ 

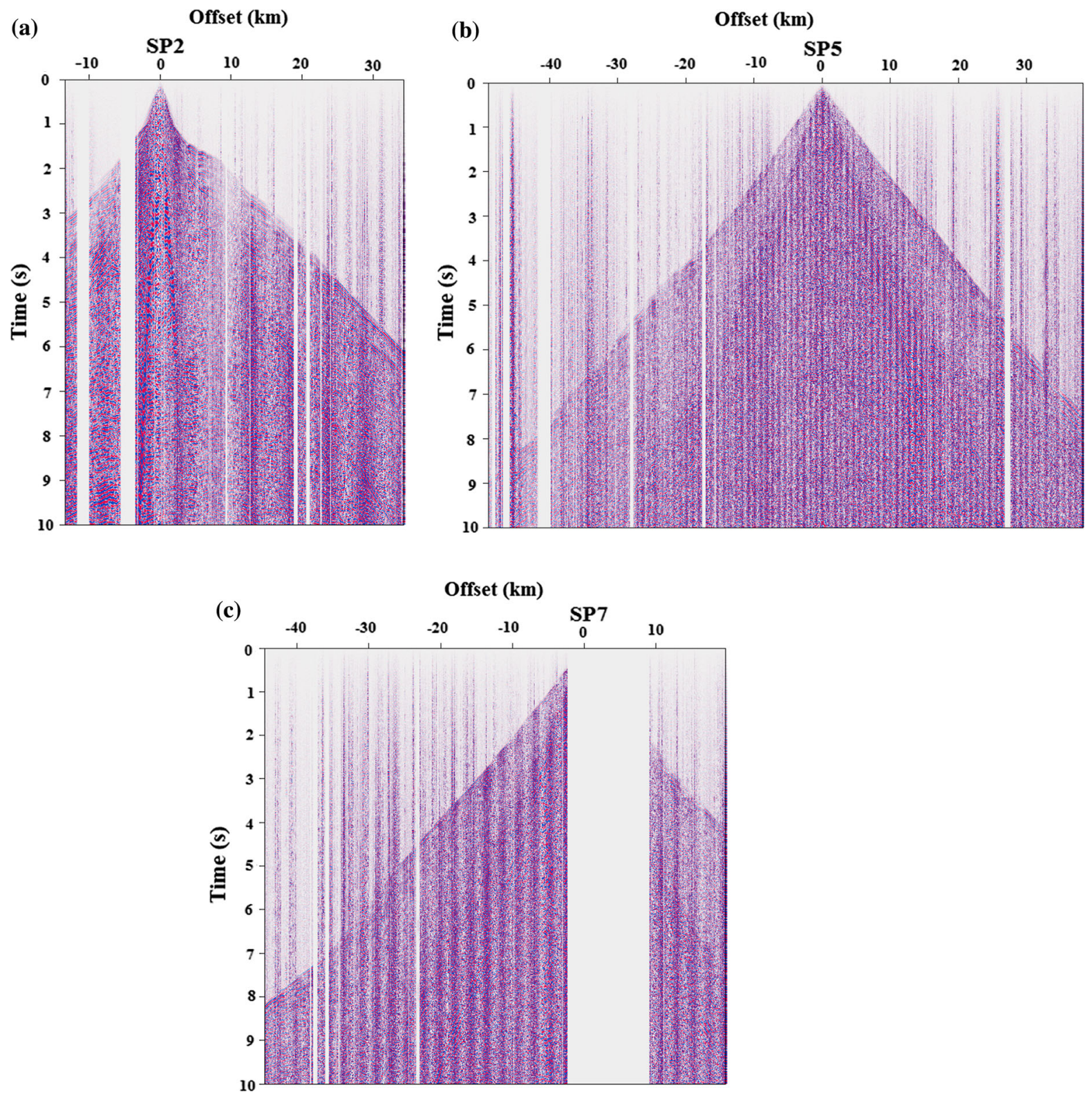

Figure 2

The wide-angle field seismic data (geometry corrected) acquired along the Sinor-Valod profile are shown for examples shot gathers. a SP2, b SP5 and c SP7 displayed in variable density mode (color) showing the coherence of the first-arrival phases and data quality used for traveltime inversion

using the radio frequency telemetry (RFT)-SN388 Sercel seismic data acquisition system. The seismic data were recorded with sampling interval (SI) of $4 \mathrm{~ms}$ having high dynamic range of $124 \mathrm{~dB}$ and wide band of frequencies up to $125 \mathrm{~Hz}$. The charge size (explosives) of each shot (made using pattern of holes with $25 \mathrm{~m}$ hole depth for each hole in which $50 \mathrm{~kg}$ explosives are loaded for blasting to generate seismic energy) varies from 50 to $450 \mathrm{~kg}$ depending upon the maximum offset coverage in which each spread length corresponds to $11.9 \mathrm{~km}$ (Behera and Sen 2014). The wide-angle seismic data acquired in the 
field along the profile in this region are first converted into individual shot gathers (SPs) by merging of different spreads to form supergathers or wide-angle SPs having minimum $0.0 \mathrm{~km}$ to maximum $\pm 50.0 \mathrm{~km}$ offset range with pre-processing of field data like application of field geometry, spherical-divergence corrections, band-pass filtering (2-5$30-80 \mathrm{~Hz}$ ) and plotted with trace normalization by minimizing the low-frequency cultural noises and groundrolls (Yilmaz 1987), which are displayed in variable density (VD) mode (color) to provide a qualitative assessment of the data quality as well as the coherency of the first-arrival phases (Fig. 2a-c) mainly used for traveltime inversion to derive the velocity model. The coherency of the first-arrivals is very strong and continued for very long-offsets as shown for example shot gathers SP2, SP5 and SP7 along the profile (Fig. 2a-c). The same example SPs are shown in Fig. 3 in reduced time scale and variable area (VA) wiggle mode (black and white) indicating different first-arrival phases picked along with the raw shot gathers without any pick of phases to provide a measure of the data quality control of the phases used for traveltime inversion. The first-arrival traveltimes were picked manually from all the nine SP gathers (Fig. 1) for ray-trace inversion to derive the velocity model. The ray-trace velocity model derived from the first-arrival traveltime inversion of these picks along with the superposition of synthetic responses on the observed data computed for the model derived shown for the representative example SPs (SP2, SP5 and SP7) along the $\mathrm{N}-\mathrm{S}$ trending 90-km-long Sinor-Valod profile (Fig. 3a-c) in the Deccan Syneclise region.

\subsection{Forward Modeling and Inversion of First- Arrival Traveltime Data}

The procedure for obtaining a $2 \mathrm{D}$ velocity structure by using refraction/wide-angle seismic reflection data involves laborious trial-and-error ray-trace forward modeling (Catchings and Mooney 1988; Zelt and Smith 1992). The most common ray-tracing algorithms for forward modeling are the ones developed by Červený et al. (1977), McMechan and Mooney (1980), and Spence et al. (1984). The theoretical response of a laterally heterogeneous
Figure 3

The observed seismic data and corresponding synthetic responses computed for the model derived using ray-trace inversion show typical shot points. a SP2, b SP5 and c SP7 along the Sinor-Valod deep seismic profile. Bottom to top of each panels: ray-tracing though the different layers indicating respective velocity values of each layer, corresponding traveltime fit of the observed (colored vertical bars) with synthetic responses (solid black line) for each layer, observed data superimposed with traveltime picks (colored dots) and modeled response (solid pink line), observed field seismic data without any traveltime picks of respective shot points. The observed and modeled data are plotted in reduced scale with reduction velocity of $7 \mathrm{~km} / \mathrm{s}$

medium is repeatedly compared with observed data until a constructed velocity model provides a good fit between the calculated and observed response. An experienced interpreter can often assess how the relevant model parameters need to be adjusted to improve the fit along one or two traveltime branches for one or few shots simultaneously. Nevertheless, forward modeling remains a time-consuming process, regardless of computer speed, due to number of iterations normally required for traveltime fit and the necessary human interactions. For seismic experiments that consist of numerous shots along a single line, it may be impossible through trial-and-error forward modeling to construct a velocity model that fits the data within acceptable limit. In addition, forward modeling cannot provide quantitative estimates of model parameter uncertainty and resolution or assess the model in terms of errors and nonuniqueness, respectively. Finally, forward modeling cannot assure that the data have been fit to minimize a particular norm (Zelt and Ellis 1988; Behera et al. 2004).

In contrast to the limitations of forward modeling, generalized linear inversion can provide estimates of the parameter uncertainty, resolution and model nonuniqueness as well as a certain level of confidence that a local minimum of a particular norm of $\chi^{2}=1$ is achieved. Methods for the inversion of crustal refraction/wide-angle reflection traveltimes in 2D media have been developed by Spence et al. (1984), Huang et al. (1986), Firbas (1987), and Lutter et al. (1990). These methods employ ray-tracing algorithms that were originally designed for forward modeling only, which limits the effectiveness of the approaches since forward modeling algorithms should be suited 

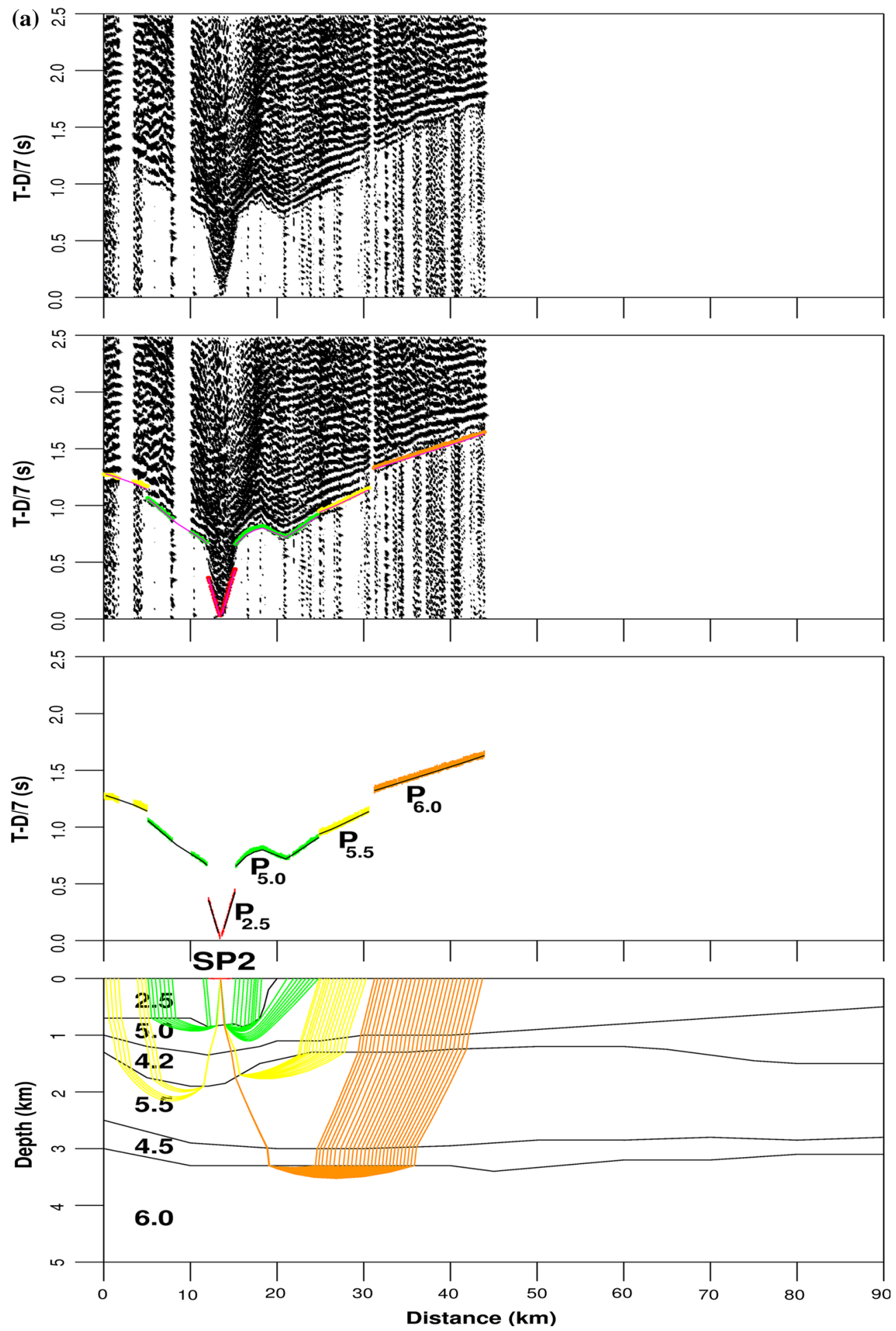

to the special needs of the inverse problem. Hence, flexible model parameterization that uses a minimum number of independent model parameters is required with a computationally efficient and robust method of ray-tracing for traveltime inversion to derive the velocity model. 


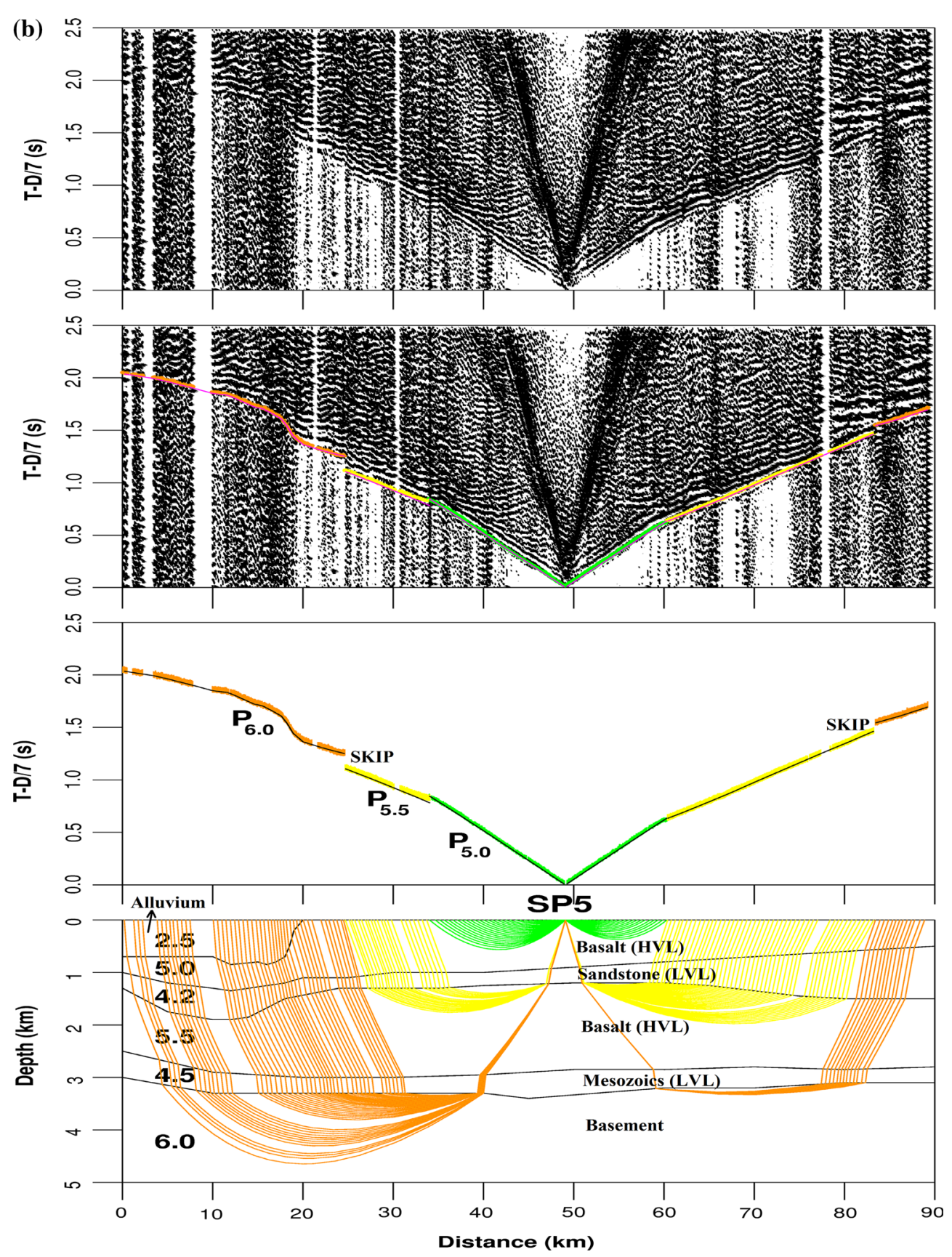

Figure 3

continued

Zelt and Smith (1992) developed a technique for inverting traveltimes to obtain $2 \mathrm{D}$ velocity and interface structure simultaneously, in which the model parameterization and method of ray-tracing are suited to the forward step of an inversion algorithm. The method is applicable to any set of traveltimes for which forward modeling is possible, regardless of the shot-receiver geometry or data quality, since the forward step is equivalent to trialand-error forward modeling. The non-linearity of 

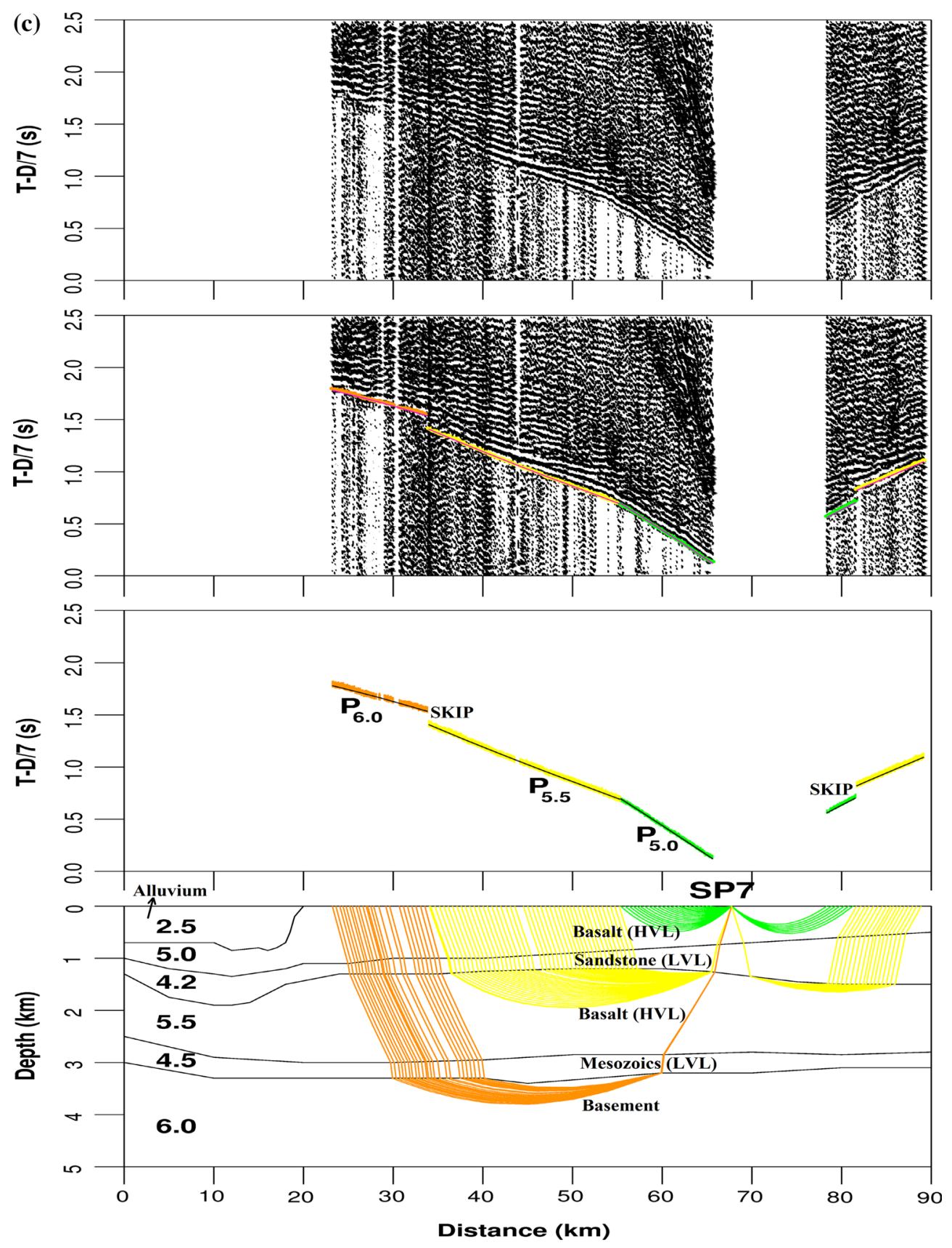

Figure 3

continued

traveltime inversion makes a starting model and iterative approach necessary, thus requiring a practical and efficient forward step. The model parameterization presented here use different layers composed of variable-sized blocks in which a minimum number of independent parameters are required to represent a typical shallow velocity model. The number and position of model parameters (velocity and boundary nodes) specifying each layer can be general and thereby adapted to the subsurface 
resolution of the data, and also allows the surface relief and near-surface velocity variations to be incorporated into the model. The method of raytracing is coupled to an automatic determination of ray take-off angles by an efficient numerical solution of the 2D ray-tracing equations. The instability associated with a blocky model parameterization is reduced by applying a smooth layer boundary simulation. The first step of the inversion is the analytic calculation of partial derivatives of traveltime with respect to the model velocities and the vertical position of boundary nodes. These partial derivatives are calculated during ray-tracing and may correspond to any arrival identified in the observed seismic traveltime data (i.e., refractions, reflections, head-waves, multiples, etc.). Traveltimes and partial derivatives are interpolated across ray endpoints to the receiver locations, avoiding the need for twopoint ray-tracing. Damped least-square inversion is used to determine the updated model parameters of those selected for adjusting both velocities and boundary nodes simultaneously.

Techniques for determining the velocity structure of the shallow sediments overlying the basalts have been well developed for conventional seismic profiling, assuming hyperbolic moveout of reflections coming from the interface between two sedimentary layers. For deeper structures down to the basement, the variations of traveltime with offset of both reflections and diving waves were picked manually from every shot gathers recorded for the wide-angle data to develop 2D velocity model along the SinorValod seismic profile in Deccan Syneclise (Fig. 1). In the present study, the linearized ray-trace traveltime modeling/inversion program RAYINVR of Zelt and Smith (1992) is used to invert the first-arrival traveltimes picked manually from each shot gathers (SPs) recorded along the profile (Fig. 3) and derived the velocity model. The velocity model delineate the extent and thickness of basalt flows within the Deccan trap, together with lower-velocity sediments that lie beneath them and in some places, strong reflections off the top of the underlying basement. The shallow sediments mainly consist in recent alluvium or weathered clastics with velocities lower than $2.5 \mathrm{~km} / \mathrm{s}$ and confined within the basinal part located between 0 and $20 \mathrm{~km}$ along the profile
(Fig. 3). There is an abrupt increase in seismic velocity at the top of the basalt flows with basalt velocities $(5.0-5.5 \mathrm{~km} / \mathrm{s})$ being well constrained by the first-arrival diving waves. The diving waves through the basement from strong first-arrivals at offsets usually in excess of $10 \mathrm{~km}$ (Fig. 3), which highlights the usefulness of long-offset seismic data, since these phases are recorded only as first-arrivals at long-offsets. Hence, the first-arrival traveltime inversion enables us with confidence to build a well constrained velocity model. The final ray-trace inversion model for all the nine wide-angle SPs along the Sinor-Valod profile in the Deccan Syneclise region is shown (Fig. 4) with the corresponding first-arrival traveltime fit of the observed data showing two thick sequences $(>1.0 \mathrm{~km})$ of high-velocity basaltic layers masking comparatively thin $(<0.5 \mathrm{~km})$ low-velocity Mesozoic sediments lying above the basement. The total number of first-arrival traveltime data picked from all the nine SPs (Fig. 3) used for ray-trace inversion (Fig. 4) is 4856 with RMS traveltime misfit $0.024 \mathrm{~s}$ and normalized $\chi^{2}$ obtained is 1.01 . The detail ray-trace inversion results are presented in Table 1.

The presence of low-velocity-layer (LVL) beneath the high-velocity-layer (HVL) is indicated by the step-back or traveltime skips in the firstarrivals (Fig. 3a-c) at long-offsets as observed in different wide-angle shot gathers along the profile (Behera and Sen 2014). In the example shown in Fig. 3, the basalt thickness varies from 0.5 to $1.5 \mathrm{~km}$, and the basalt diving rays terminate at about $15-20 \mathrm{~km}$ of offset because the velocity gradient in the basalt layer is such that diving rays cannot penetrate deeper into the basalt without going through its base. The range at which the basalt diving wave terminate depends primarily on the basalt thickness and its vertical velocity gradient (Fliedner and White 2001; Fruehn et al. 2001). In reality, because the seismic energy travel as waves, the amplitude of the basalt diving waves do not drop abruptly to zero at the far offsets, but decreases gradually below the background noise level causing traveltime skips as observed in different shot gathers modeled (Fig. 3). The two sequences of LVLs sandwiched within the thick column of HVLs formed by basalt/trap and basement that are constrained by 


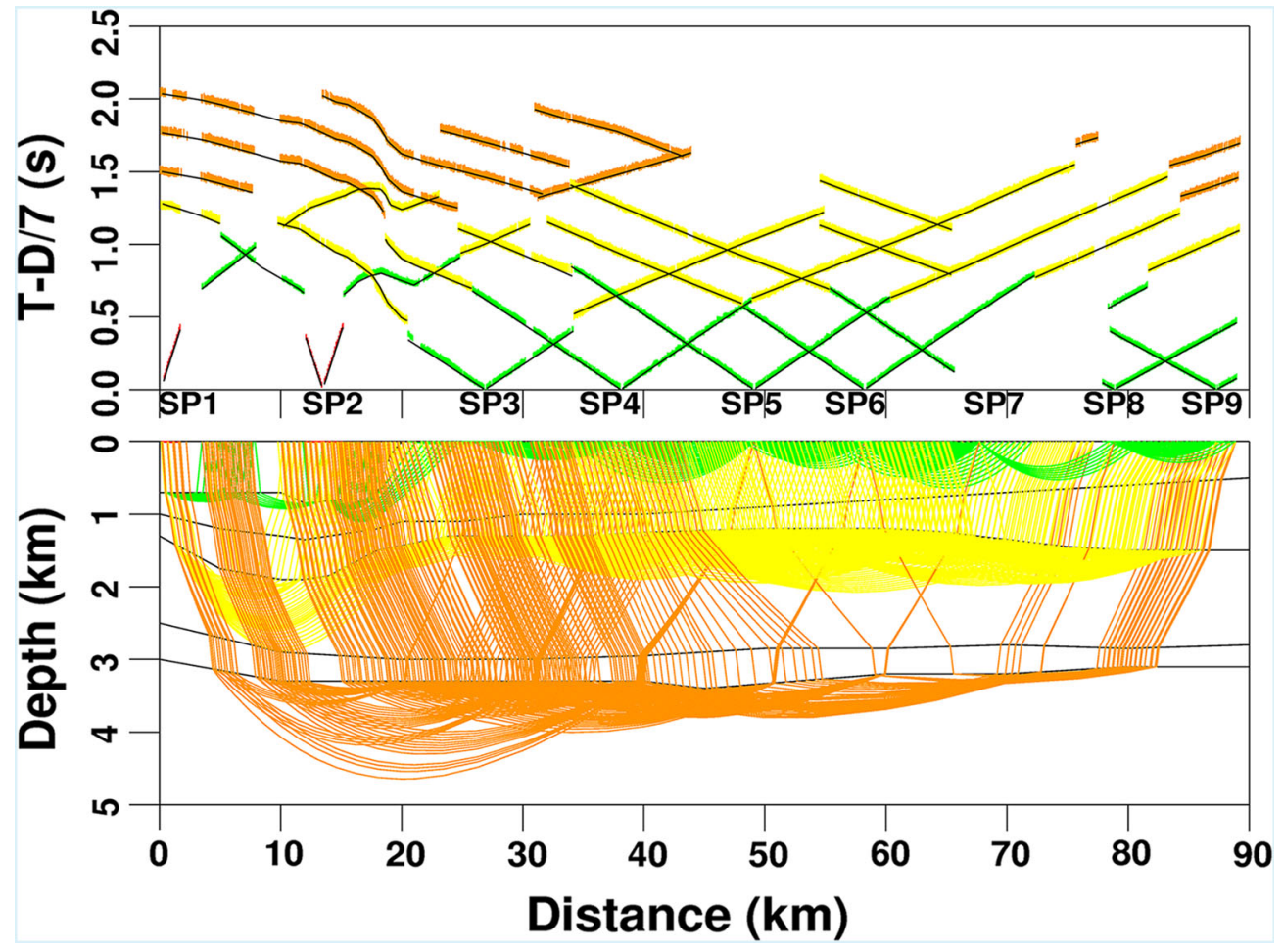

Figure 4

The ray-trace inversion model (bottom panel) along the Sinor-Valod seismic profile showing rays traced through each layer from all the shot points recorded (SP1-SP9) along the profile. The corresponding picked first-arrival traveltime data (colored bars) for all the SPs and the computed responses (solid black line) for each layer from the model derived are superimposed to indicate the nature of traveltime fit (top panel) plotted in reduced scale with a reduction velocity of $7 \mathrm{~km} / \mathrm{s}$

Table 1

Ray-trace inversion results along Sinor-Valod profile

\begin{tabular}{lcllrr}
\hline Phases & No. of data picked & Data uncertainty (ms) & RMS residuals (s) & Normalized $\chi^{2}$ value $\begin{array}{r}\text { No. of rays traced } \\
\text { through the model }\end{array}$ \\
\hline$P_{1(2.5)}$ & 48 & 20 & 0.022 & 0.913 & 48 \\
$P_{2(5.0)}$ & 1511 & 20 & 0.019 & 1.062 & 1471 \\
$P_{4(5.5)}$ & 2141 & 30 & 0.029 & 1.094 & 2141 \\
$P_{6(6.0)}$ & 1196 & 30 & 0.028 & 0.981 & 1196 \\
\hline
\end{tabular}

the analysis of first-arrival traveltime data (Fig. 3), are correlative with findings coming from a well drilled nearby Ankleswar (Fig. 1) having $5.7 \mathrm{~km}$ total depth (TD) in which trap thickness obtained is 3.2 km (Roy 1991; Tewari et al. 1995; Dixit et al. 2010). This also explains the velocity inversion documented by the ray-tracing response derived from first-arrival traveltime data along the Sinor-Valod seismic profile due to presence of LVLs hidden below the HVLs (Fig. 4).

\subsection{Elastic Finite-Difference Full-Wave Modeling}

The first level of interpretation derived from forward modeling and inversion of first-arrival traveltime data can be strengthened by generating synthetic seismic data using elastic finite-difference full-wave modeling. Seismic wave propagation through the real earth is generally expressed by wave equations, which are based on Newton's second law of motion and Hooke's law of elasticity. Here, we consider a $2 \mathrm{D}$ elastic and isotropic medium with a 


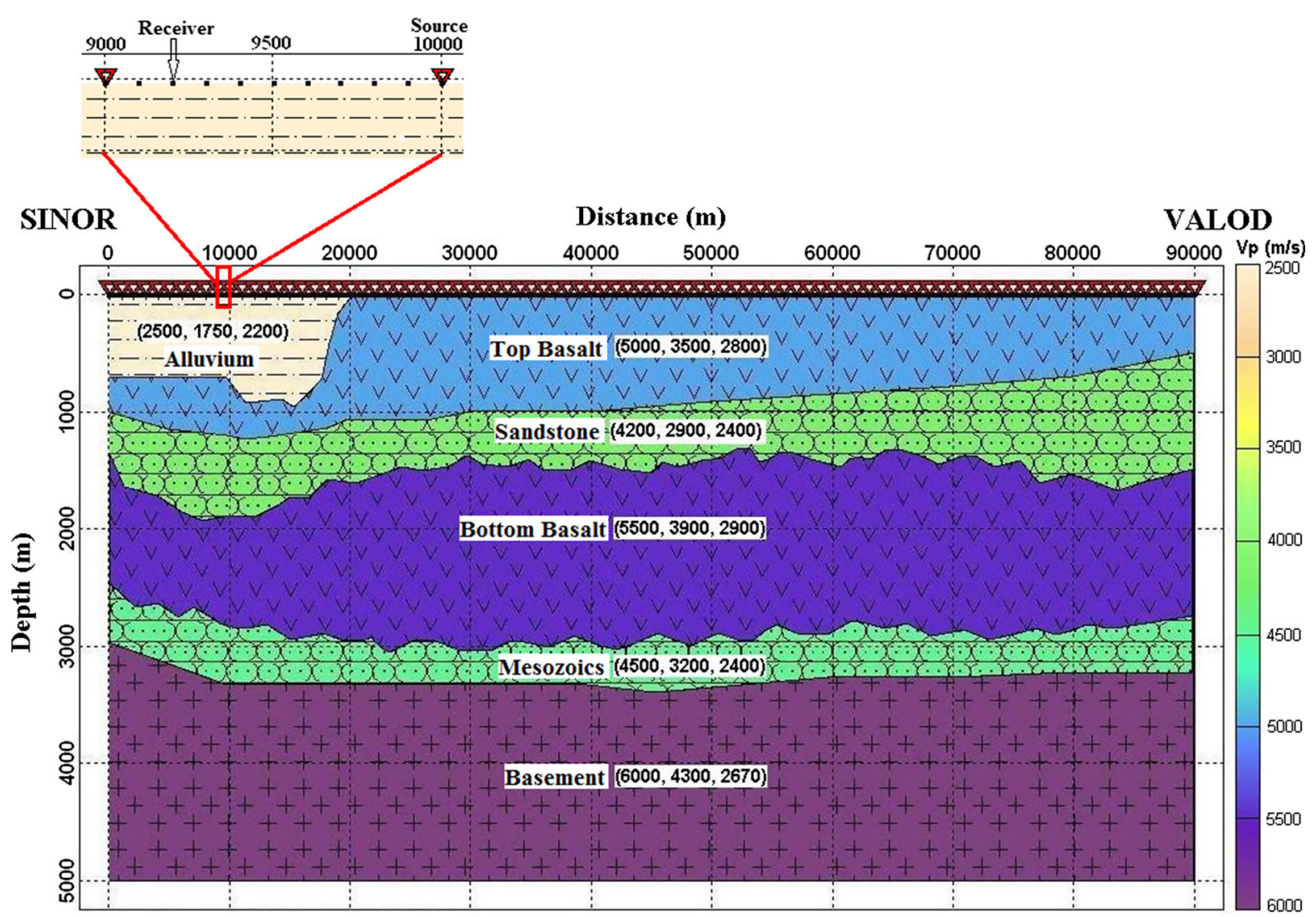

Figure 5

The same ray-trace inversion velocity model (Fig. 4) derived along the N-S trending Sinor-Valod deep seismic profile is used with addition of rugosity for the bottom basalt layer (to make it more heterogeneous) lying directly above the Mesozoic sediments for generation of full-wave synthetic seismic data using elastic finite-difference full-wave modeling approach. The average $P$-wave velocity $\left(V_{P}\right), S$-wave velocity $\left(V_{S}\right)$ and density $(\rho)$ of each layer are marked with the corresponding values (i.e., $5500,3900 \mathrm{~m} / \mathrm{s}, 2900 \mathrm{~kg} / \mathrm{m}^{3}$ ) as well as labeled according to their lithologies with different patterns corresponding to the rock types, respectively. All the model dimensions are shown in (m) for defining the exact grid points while making staggered-grid elastic finite-difference computations. The sources (shots) are marked as inverted triangles (red) and receivers (geophones) are marked as dots (black) along the profile having source interval of $1 \mathrm{~km}$ and receiver interval of $100 \mathrm{~m}$. For clarity about the source and receiver positions, it is zoomed and displayed on the top it as inset

horizontal $x$-axis and vertical $z$-axis for model distance and depth, respectively. The wave equations that describe the propagation of seismic waves for this medium are (Virieux 1986):

$$
\begin{gathered}
\rho \frac{\partial^{2} u}{\partial t^{2}}=(\lambda+2 \mu)\left(\frac{\partial^{2} u}{\partial x^{2}}+\frac{\partial^{2} w}{\partial x \partial z}\right)+\mu\left(\frac{\partial^{2} u}{\partial z^{2}}-\frac{\partial^{2} w}{\partial x \partial z}\right), \\
\rho \frac{\partial^{2} w}{\partial t^{2}}=(\lambda+2 \mu)\left(\frac{\partial^{2} u}{\partial x \partial z}+\frac{\partial^{2} w}{\partial z^{2}}\right)+\mu\left(\frac{\partial^{2} w}{\partial x^{2}}-\frac{\partial^{2} u}{\partial x \partial z}\right),
\end{gathered}
$$

where $u$ and $w$ are horizontal and vertical displacements, $t$ is time of wave propagation, $\lambda$ and $\mu$ are
Lame's first and second parameters, respectively, and $\rho$ is the density of the medium. Here we have applied the staggered-grid finite-difference scheme (Virieux 1984, 1986; Levander 1988; Graves 1996; Yang et al. 2014) for discretization of the above wave equations (e.g., Eqs. 1 and 2). To reduce spurious reflections from the sides and bottom of the computational grid, we apply absorbing boundary conditions, which are especially very efficient in absorbing the Rayleigh waves at the free surface. The horizontally propagating waves striking the side boundaries and vertically propagating waves striking the bottom boundary are also absorbed. The top of the model is a free surface, where shots and receivers are located, 

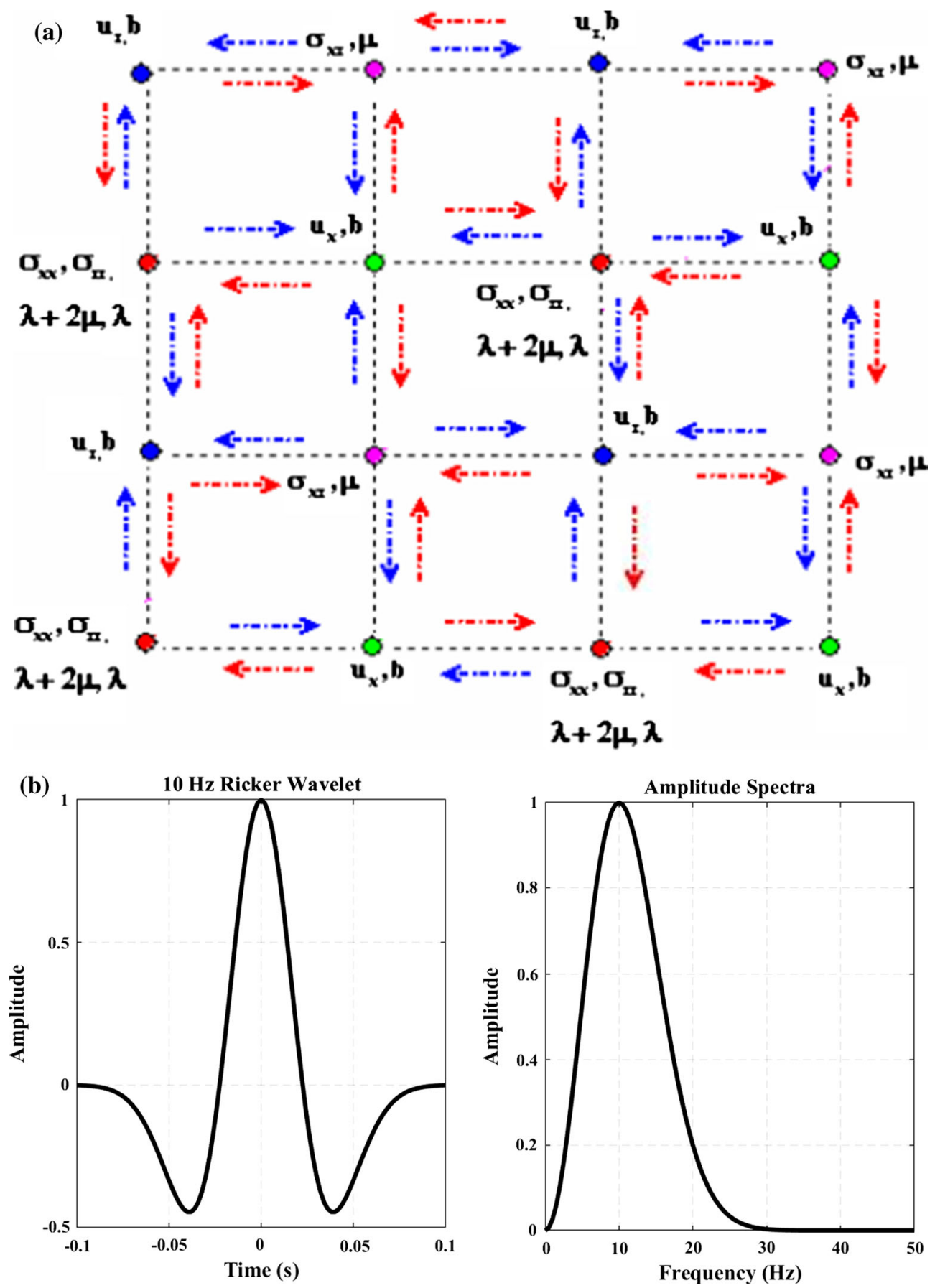

Figure 6

a Staggered-grid scheme for computation of 2D elastic wavefield. Arrows are denoting spatial differentiation. Red colored arrows denote how the derivative operator shift forward or backward to compute stresses. Blue colored arrows show how the derivative operators shift forward or backward to compute particle accelerations from the stresses. Here the buoyancy $b=\frac{1}{\rho}, \rho$ is the density of the medium. b $10 \mathrm{~Hz}$ Ricker wavelet source time function used as input for the generation of full-wave synthetic seismic data for the velocity model (Fig. 5) and its corresponding amplitude spectra 
which is an air-solid boundary and here we put shearstress to be zero at time $t=0$. The stability of this system is given by Von Neumann's condition:

$$
\frac{1}{\sqrt{2}}\left(\sqrt{V_{\mathrm{p}}^{2}+V_{\mathrm{s}}^{2}}\right) \frac{\Delta t}{\Delta x}<1,
$$

where $V_{\mathrm{p}}=\sqrt{\frac{\lambda+2 \mu}{\rho}}$ and $V_{\mathrm{s}}=\sqrt{\frac{\mu}{\rho}}, \Delta t$ and $\Delta x$ are the grid steps in time and space axes, respectively (in this case $\Delta x=\Delta z$ ). In order to avoid grid dispersion, we use $\frac{\Delta x}{\xi}<0.1$, where $\xi$ is the wavelength. Here, at least 10 grid spacing are used to sample the wavelength.

We have used symmetrical and compressional point source with a dominant frequency of $10 \mathrm{~Hz}$ to excite the seismic wave field because geophones with same natural frequency are used for recording data along the Sinor-Valod seismic profile (Behera and Sen 2014). The source time function is the first order derivative of the Gaussian function, which is a Ricker wavelet expressed as:

$$
S(t)=\left(t-t_{0}\right) e^{-\left(\pi f_{0}\left(t-t_{0}\right)\right) 2} .
$$

where $f_{0}$ is dominant frequency and $t_{0}$ is the central time of the wavelet. The model derived along the Sinor-Valod profile with interval velocities of each layer (Fig. 5) has been used to generate synthetic seismic data and snapshots of seismic wave field by using elastic finite-difference full-wave modeling. For this model, the synthetic seismic data have been acquired for 91 shot gathers (SPs) with $1 \mathrm{~km}$ shot intervals and 901 stationary receivers with $100 \mathrm{~m}$ receiver intervals correlating the same data acquisition geometry used along the Sinor-Valod profile except for very close SP intervals (Fig. 5). The synthetic seismic data generated for the model has sampling interval (SI) of $2 \mathrm{~ms}$ and record length $4 \mathrm{~s}$. We have used a robust 2D staggered-grid computing scheme (Fig. 6a) for numerical modeling using the $10 \mathrm{~Hz}$ Ricker wavelet (Fig. 6b) and wave propagation through the model to penetrate the seismic energy below the thick column of basalt layers to image hydrocarbon-bearing sub-trappean Mesozoic sediments hidden beneath it. The different parameters used in the staggered-grid approach are represented at all the grid points, e.g., normal-stresses $\sigma_{x x}, \sigma_{z z}$ and elastic parameters $\lambda, \lambda+2 \mu$ are represented by green circles, shear-stress $\sigma_{x z}$ and $\mu$ are represented by blue circles, velocity $u_{x}$ along $x$-direction and buoyancy $b$
Figure 7

Example of synthetic shot gathers (data) generated by the elastic finite-difference full-wave modeling using staggered-grid computing scheme are shown for shot points. a SP11, b SP51 and c SP71 along the 90-km-long profile. The different phases obtained through full-wave modeling are clearly seen for each shot; however, the reflections from top and bottom basalts having large impedance contrast with the sediments lying below have strong amplitude build-up and polarity reversals along with presence of other phases like direct arrivals, multiples, diffractions, scatterings and converted waves, which are labeled on the shot gather for clarity. The amplitude spectra (normalized) of respective shot gathers are also shown as inset for each shot having peak frequency near $10 \mathrm{~Hz}$ and plotted up to the Nyquist frequency $(250 \mathrm{~Hz})$ to see the nature of variations of amplitude with respect to frequency

are represented by red circles, velocity $u_{z}$ along $z$ direction and buoyancy $b$ are represented by purple circles (Fig. 6a). For the elastic finite-difference fullwave modeling, we have used spatial sample step of $5 \mathrm{~m}$ and temporal step of $2 \mathrm{~ms}$ for stable computations satisfying Eq. (3) of Von Neumann's condition.

\section{Full-Wave Synthetic Seismic Data for Sinor- Valod Profile}

The shot gathers generated for the model (Fig. 5) show all the different types of phases like direct arrivals, reflections from each interfaces, multiples, converted waves except the groundrolls, which has been restricted while modeling (Fig. 7). The groundrolls significantly reduces the primary reflection energy to penetrate deep into the basalt layers and hinders in the wave propagation and hence was restricted from computation. The shot gathers indicate significant transmission of energy below the basalt with different types of arrivals as shown in the example shot gather SP11 (Fig. 7a). The reflections from each layer, multiples and other arrivals such as converted waves, diffractions are marked in example shot gather SP51 (Fig. 7b) with the corresponding lithology as mentioned in the model (Fig. 5) used to generate the full-wave synthetic seismic data along with their amplitude spectrum (Fig. 7a-c).

The nature of wave propagation through the model can be seen from the snapshots generated for different shot gathers at time steps of 0.5, 1.0, 2.0 and 


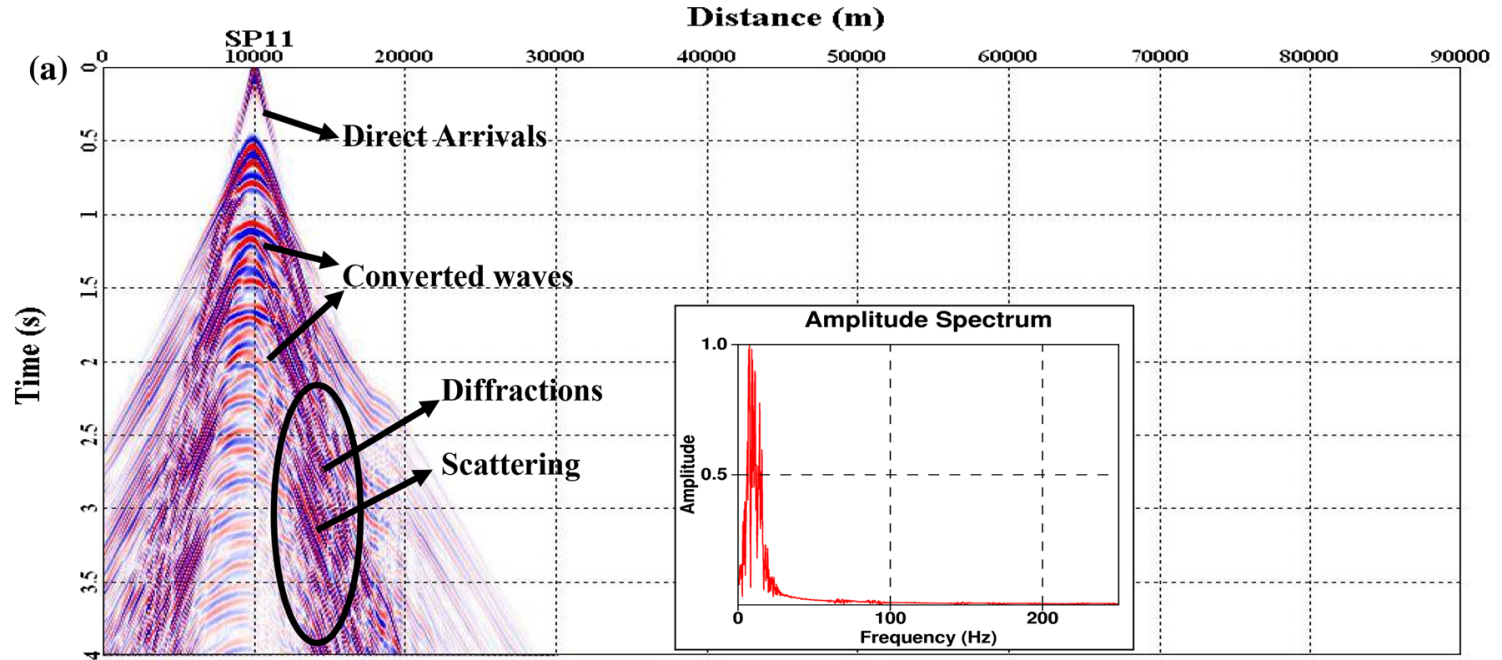

Distance (m)
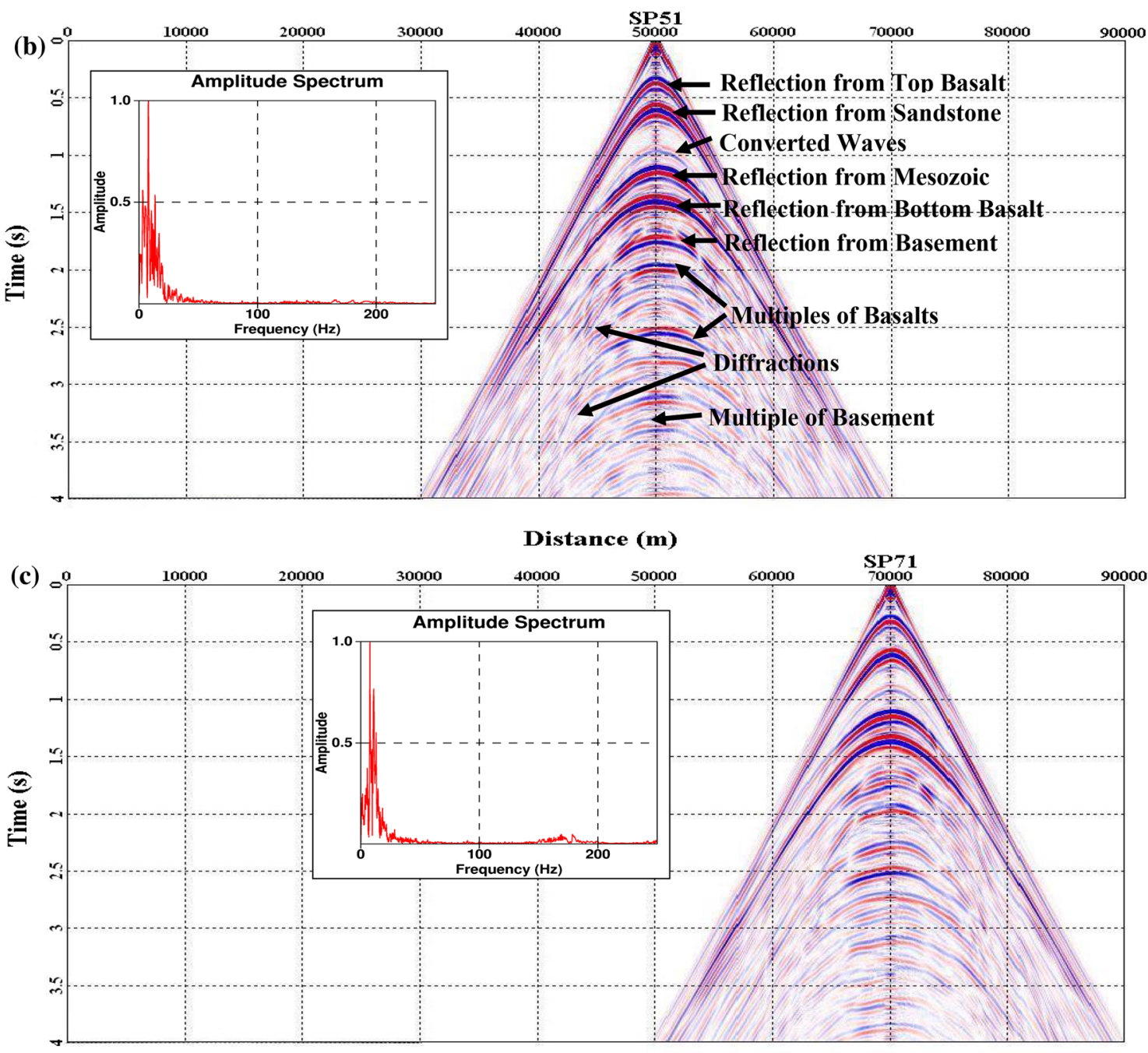

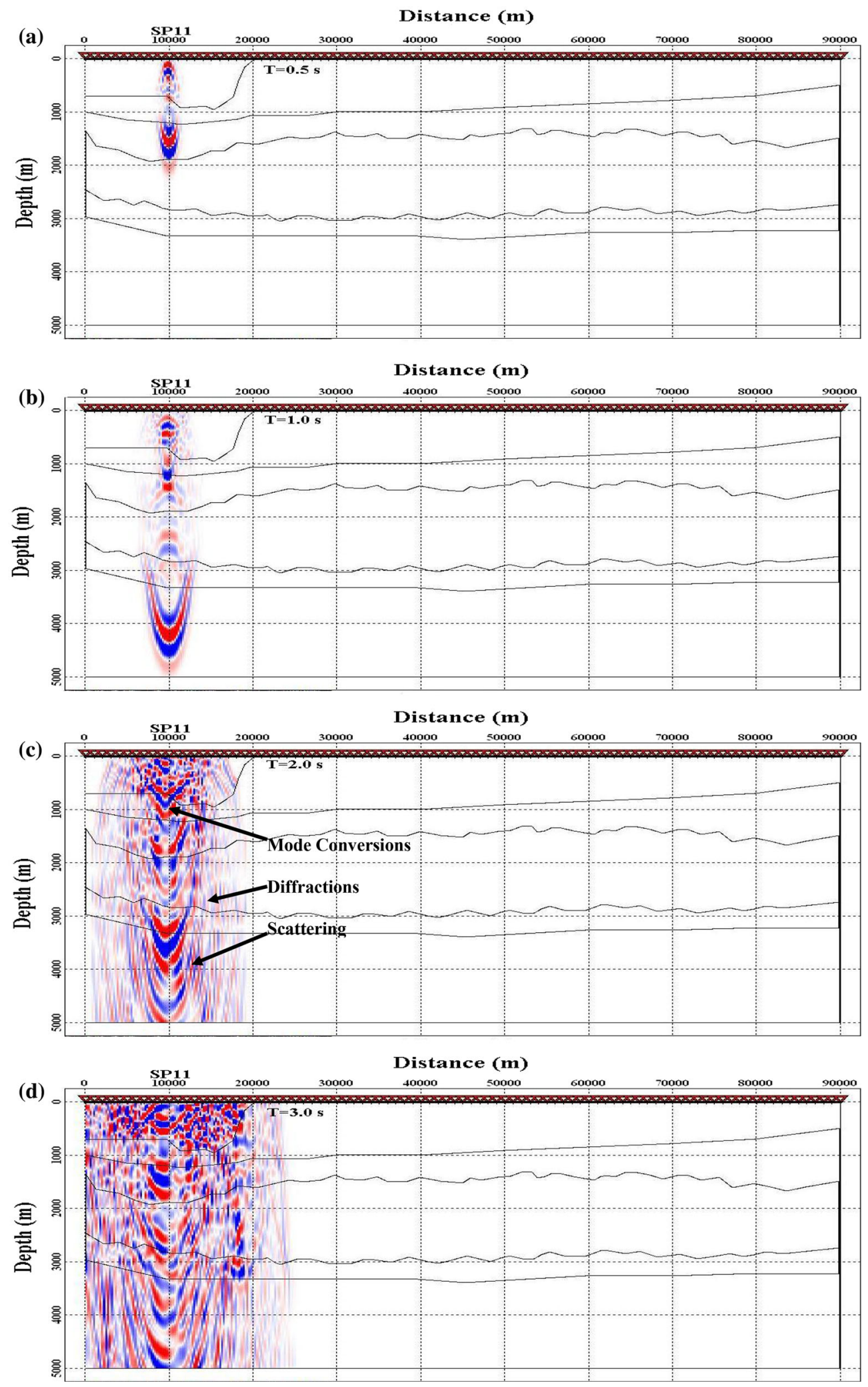
Figure 8

Snapshots of elastic wave propagation shown for the example shot point SP11 at different times a $T=0.5 \mathrm{~s}, \mathbf{b} T=1.0 \mathrm{~s}, \mathbf{c} T=2.0 \mathrm{~s}$, d $T=3.0 \mathrm{~s}$, respectively. These snapshots show the complexity of wave propagation through the model due to scattering, modeconversions, diffractions, etc., when it reaches the rugose basalt layer having uneven rough interface at $T=2.0 \mathrm{~s}$ simulating the real subsurface velocity model. The inverted triangles represent the individual shot point locations along the profile and black squares on the surface are the receivers

3.0 s, respectively (Fig. 8a-d). The complexity of the wavefield generated at different times within the model indicate the nature of wave propagation with reflections, mode-conversions, diffractions and scattering at different interfaces due to the elastic finitedifference full-wave modeling, which is presented for the example shot gather SP11 at a distance of $10,000 \mathrm{~m}$ of the model (Fig. 8). The reflection and transmission of energy through the model is governed by the Snell's law. When a wave encounters the interface between two media, then part of the energy of the incident wave is reflected back and part is transmitted to the second media. In this case when the $P$-wave encounters the high-velocity basalt layer having very high impedance contrast of the basaltsediment interfaces along with rugose bottom basalt layer, the waves reflected and transmitted becomes very complex as shown for time of wave propagation at 2.0 and $3.0 \mathrm{~s}$ of the snapshots for SP11 (Fig. 8c, d). As a whole it is clear that significant amount of energy has been transmitted down below the two thick basalt layers with mode-conversion and again reflected back from bottom of the layer without generation of spurious numerical waves from the side and the bottom boundaries of the model because of the use of absorbing boundary conditions with staggered-grid computing scheme (computations at both grid points and half-grid points) while elastic finitedifference full-wave modeling. The snapshots of the wave propagation at different times (Fig. 8) provide a very good insight of the elastic wave propagation through the model, which has produced the full-wave synthetic seismic data (Fig. 7) depicting all the phases with clear sub-basalt arrivals for imaging sediments hidden below the basalt.

\section{Full-Wave Synthetic Seismic Data Processing}

To obtain a stack section of the full-wave synthetic seismic data generated (Fig. 7) along the Sinor-Valod profile, we have adopted the pre-stack seismic data processing flow (Table 2) of Yilmaz (1987). The multiples present in the data are very severe and have been reduced using the predictive deconvolution (Table 2) without affecting the amplitude of the primary reflections from different layer interfaces. After application of spherical-divergence correction with proper gain recovery function, filtering and deconvolution (spiking and predictive), the shot gathers were muted for first-arrivals and deeper mode-conversions (both top and bottom mute), followed by velocity analysis and picking of the RMS velocities from the coherency semblance spectra generated for each gather with

Table 2

Seismic data processing workflow

Pre-stack data processing of full-wave synthetic seismic data

1. Input synthetic shot gathers (no. of shots: 91 , SI: $2 \mathrm{~ms}$, record length: $4 \mathrm{~s}$ )

2. Spherical-divergence correction (gain recovery function $\mathrm{T}^{2} \mathrm{~V}^{1}$ )

3. Band-pass filtering $(5-10-40-50 \mathrm{~Hz})$

4. Spiking deconvolution (OL: 0.060 s, PL:0.002 s, PPW:0.1\%)

5. Predictive deconvolution (OL: 0.040 s, PL: 0.004 s, PPW: $0.1 \%$ )

6. Velocity analysis and create RMS velocity section

7. Mute (top and bottom mute) $\ldots \rightarrow$ Stack

8. Kirchhoff pre-stack time migration (PSTM) using the same RMS velocity values with smoothing as obtained during the above velocity analysis ... $\rightarrow$ Stack

9. Traveltime table computations for each gathers using Kirchhoff algorithm with depth step $5 \mathrm{~m}$ and time step $2 \mathrm{~ms}$

10. Kirchhoff pre-stack depth migration (PSDM) using the above traveltime table and Dix converted smoothed RMS velocity to interval velocity for the same model $\ldots \rightarrow$ Stack 


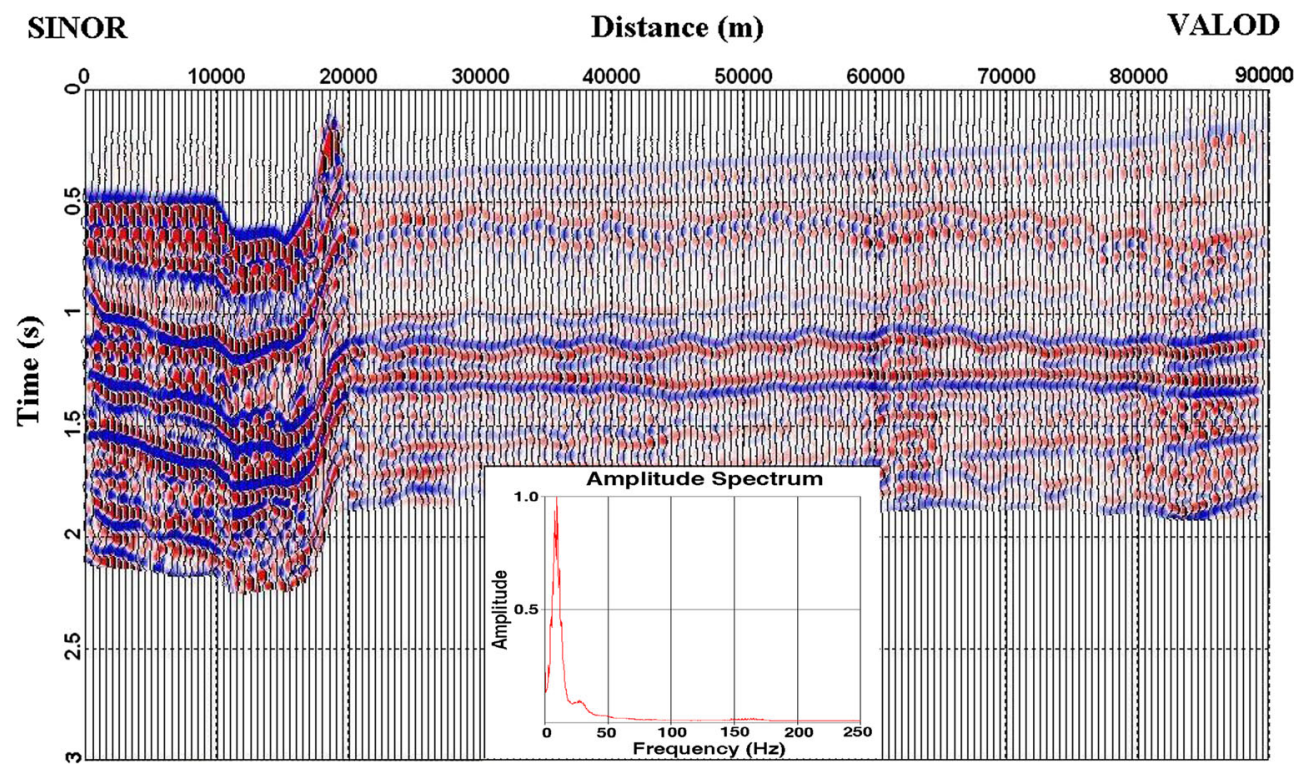

Figure 9

Seismic stack section obtained using the conventional data processing flow (Table 2) applied to the synthetic seismic data generated along the Sinor-Valod profile showing all the structural features of the derived velocity model (Fig. 5). The average amplitude spectra (normalized) of the stack section is also displayed as inset

normal moveout (NMO) correction and stacking (Table 2) to obtain the conventional stack section (Fig. 9). The stack section is the preliminary result obtained to decipher different structural features present along the Sinor-Valod profile in time domain. The stack section (Fig. 9) has delineated all the horizons along the profile correlating different layer interfaces as shown in the derived velocity model (Fig. 5). The stack section provides first-hand information about the geological structures of the study region with seismic amplitudes along the zero-offset traces (Fig. 9). Since the subsurface of this region is complex, it is necessary to improve the stack section. This can be achieved by imaging the seismic data both in time and depth domains using pre-stack time and depth migrations because post-stack migration could not improve the seismic image due to the presence of thick basalts with subsurface geological complexity.

\section{Pre-stack Time and Depth Migrations}

Conventional seismic data processing did not allow to image below the rugose Deccan basalts
(Fig. 9). Hence, we have applied Kirchhoff pre-stack time and depth migration (PSTM and PSDM) techniques to the synthetic seismic data (Fig. 7). The same pre-stack processing workflow (Table 2) is used for obtaining PSTM seismic image of the synthetic gathers using smoothed RMS velocity picked during semblance velocity analysis for stacking. The PSTM image (Fig. 10) along the profile provides significant improvement with respect to the conventional stack section (Fig. 9) by collapsing diffractions and eliminating spurious noises to make the reflections prominent. Now it is possible to know the extension and continuity of different subsurface geological structures with proper positioning of the reflections in the time domain. The top and bottom basalt layers as well as sub-trappean top sandstone and Mesozoic sediments along with basement reflections are also better imaged using PSTM. The whole profile can be divided into two different segments based on the difference in amplitude content over the entire data within the section toward left and right of the deep basinal fault (Fig. 10). The amplitude difference occurs mainly because of the presence of faults having lower SNR in the basinal part in which there are strong multiples/reverberations occur due to 


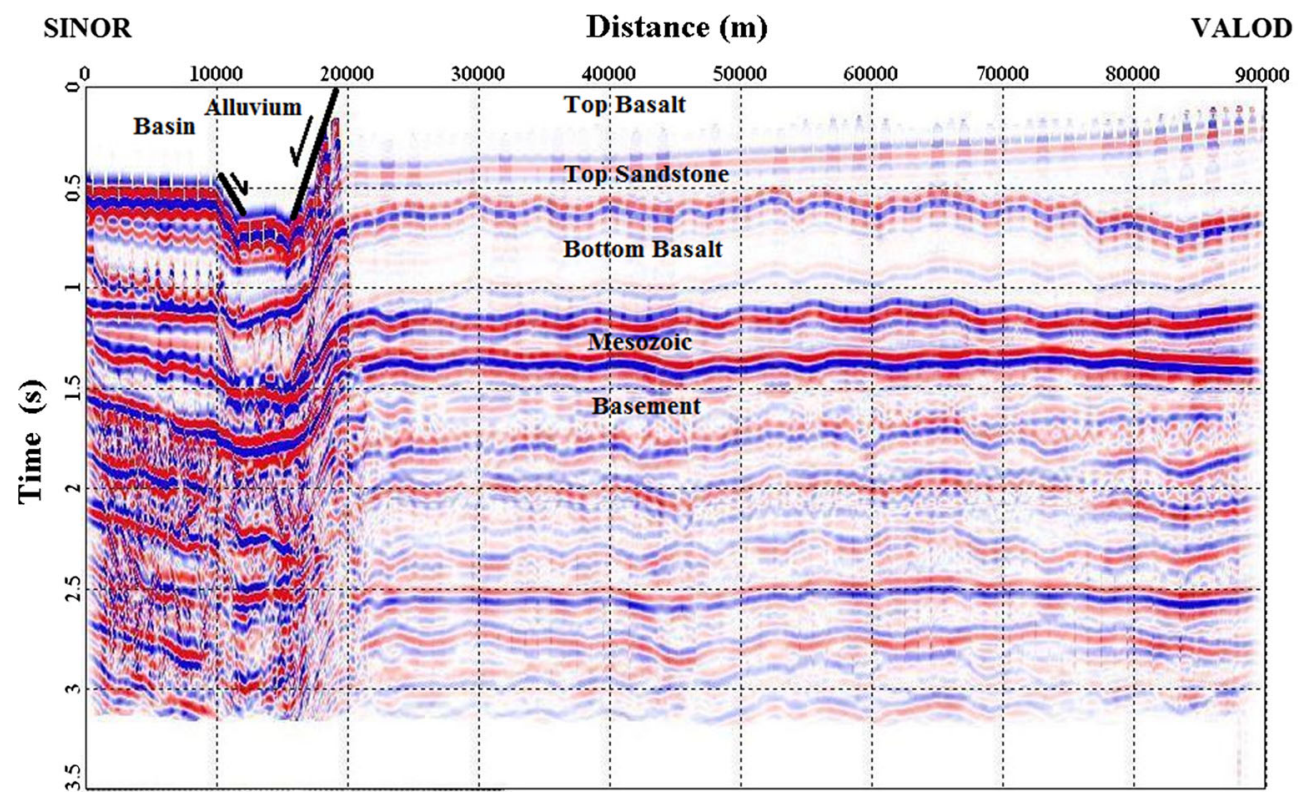

Figure 10

Stacked section obtained with Kirchhoff pre-stack time migration (PSTM) of the full-wave synthetic seismic data. The two flows of the basalt are also clearly imaged with uneven interfaces indicating rugose bottom basalt layer. The sedimentary basin structure is also imaged toward Sinor having deep basinal faults marked as the boundary between the basin and trap-covered regions along the profile. The two sequences of sub-trappean sediments corresponding to top sandstone and Mesozoics hidden below the basalts are imaged along with the basement correlating very well with the velocity model derived along the profile (Fig. 5)

presence of thick sediments on the top as well as scattering due to the faults and development of fault shadows. On the other hand, there is strong attenuation due to presence of thick column of top basalt in the right of the fault with presence of multiples and converted waves, but relatively high SNR due to strong impedance contrast of basalt and sediment interfaces. Although there are presence of modeconverted phases and base basalt multiples, which are not eliminated by application of bottom muting to avoid missing the reflections associated with the target, these phases show continuity of apparent reflections in the deeper part of the image below $2.5 \mathrm{~s}$ (Fig. 10). These reflections show significant decay in amplitude between 20,000 and 90,000 $\mathrm{m}$ of the profile distance and are slightly affecting the seismic image due to deeper penetration within the model. To overcome imaging problems related to the abovementioned coherent noises as well as position with focusing of the reflections corresponding to the true subsurface geology of the model and for better interpretation in depth domain, the computation of the pre-stack depth migrated seismic image along the profile is desired.

Pre-stack depth migration is the most accurate seismic solution for imaging complex subsurface geological structures because of its ability to focus and position the reflections in the context of strong velocity variations in the basalt-covered Deccan Syneclise region of India. The key to successful imaging using PSDM is accurate velocity model building, because it allows migration algorithms to account for proper seismic wave propagation and ray path bending in the depth domain. Hence, PSDM image provides better quality and a more plausible geologic structure than the PSTM section. We have employed the Kirchhoff PSDM technique (Yilmaz 1987; Zelt et al. 1998) to the same full-wave synthetic seismic data displayed on Fig. 7 to obtain a depth-converted image (Fig. 11). Migration operators (aperture and depth step) were chosen using an efficient ray-tracer for computing accurate traveltimes (Fig. 12) through the model for all the shot gathers along the profile. The traveltime table is used to 


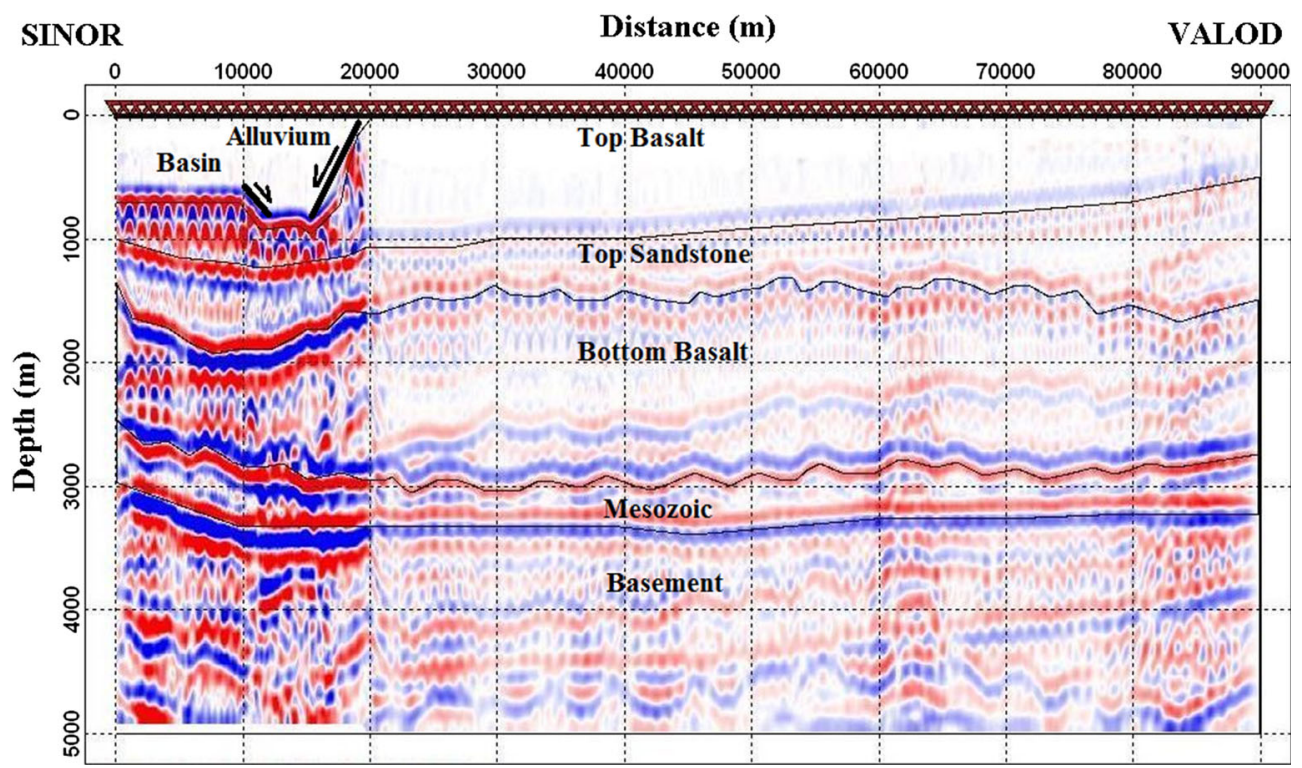

Figure 11

Kirchhoff pre-stack depth migration (PSDM) seismic image obtained along the Sinor-Valod profile superimposed on the background velocity model interfaces, which shows accurate structural details as well as different velocity layers free from most of the noises and correlated very well with the model derived from this study indicating the rugose bottom basalt as well as the hydrocarbon-bearing Mesozoic sediments hidden below the basalt lying above the basement

estimate the efficiency of the wave propagation through the high-velocity basaltic traps and the subtle variations of traveltime due to the presence of smallscale uneven and rugose basalt interfaces as well as other structural features within the model. The nature of variation of traveltime through the model is a measure of how the velocity variations and heterogeneity plays an important role for imaging these small-scale subtle geological structures of interest (Fig. 12). The accuracy of the computed traveltime handles very subtle low-velocity layers (Mesozoics) hidden below the highly rugose high-velocity basalts along with the basement. The PSDM seismic image (Fig. 11) is able to overcome all the imaging issues of focusing and positioning construed in the PSTM section (Fig. 10) as dipping reflectors and subtle subsurface geological structures like hydrocarbonbearing Mesozoic sediments lying below the thick column of basalts are now well resolved. The different layer boundaries are exactly matching with the corresponding seismic image as converted phases, diffractions, scattering and multiples that were present in the deeper part of the PSTM image are now eliminated. The peak frequency in the time domain is about twice the peak wave number in the depth domain. Hence, there is decrease in wave number with depth due to the presence of thick high-velocity basalt layers within the model as well as lower frequency content in the PSDM section (Fig. 11) as compared to the PSTM section (Fig. 10). The PSDM image (Fig. 11) is indeed very accurate and allows to clearly depict the thickness and depth extension of the different layer geometries of the input velocity model (Fig. 5).

\section{Geological Interpretation}

The PSDM seismic image (Fig. 11) has been superimposed on the background velocity model (Fig. 5) to facilitate geological interpretation. The section shows good correlation between reflections and velocities. The amplitude variation of different layers within the section as well as phase changes

Figure 12

The computed traveltime tables shown for example shot points. a SP11, b SP51 and c SP71, which are used in obtaining the Kirchhoff PSDM seismic image (Fig. 11) along the profile 

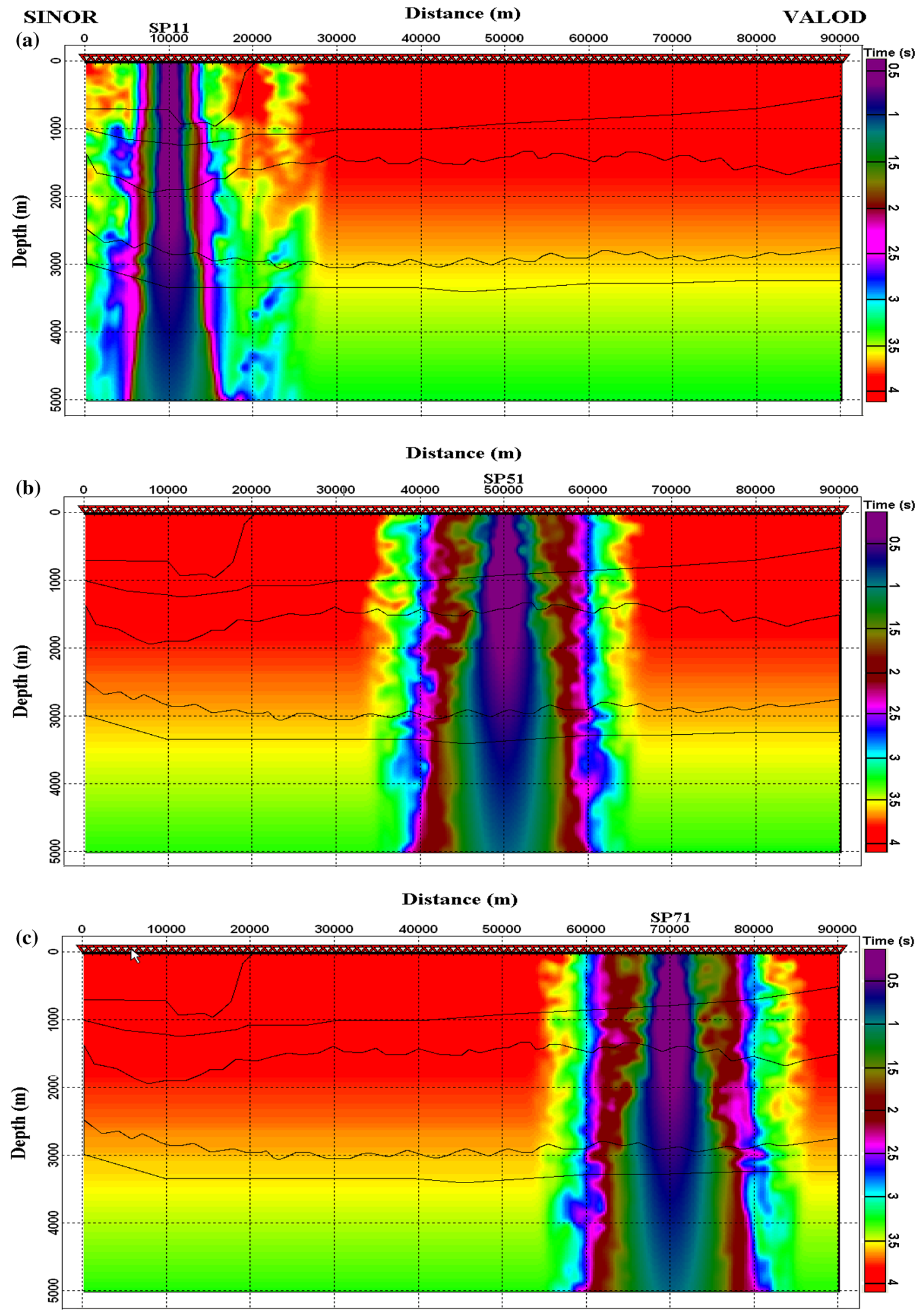


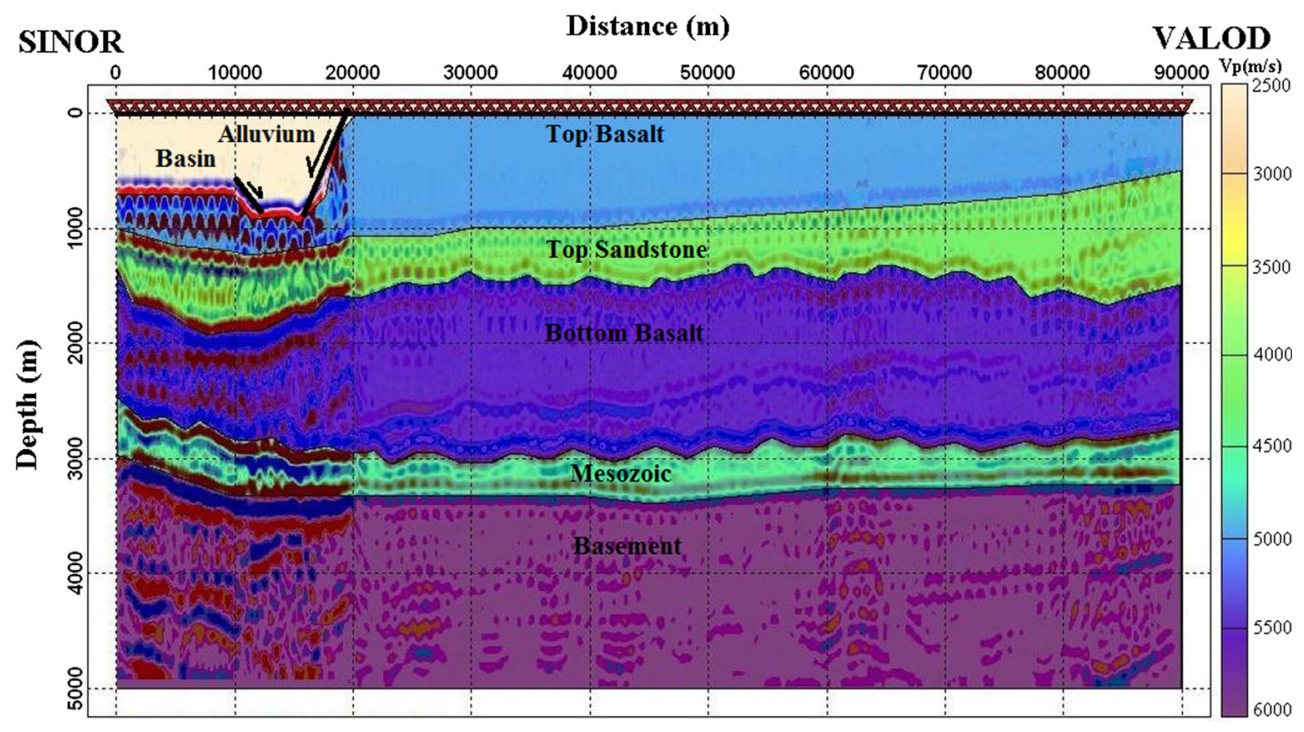

Figure 13

The interpreted PSDM seismic image superimposed on the background $P$-wave velocity $(V \mathrm{p})$ model along the Sinor-Valod profile. The $P$ wave velocity variation of the model is indicated by the color scale

depending upon the impedance contrasts of different lithological units can be easily observed. The earlier tomographic study in this region along the profile has provided very good insight of the smooth velocity variations with prominent subsurface geological structures and their corresponding velocity and thicknesses (Behera and Sen 2014). We have extended the results to build complete PSDM seismic image along the profile with fine-scale horizons of sub-trappean Mesozoic sediments hidden below the thick basalts as trap, sedimentary basin as well as the basement configuration. The dipping faults and extension of the sedimentary basin along with all the lithological units (Fig. 5) have been successfully imaged (Fig. 13) with the help of robust Kirchhoff PSDM technique applied to the full-wave synthetic seismic data generated for the model (Fig. 5) in very close shot intervals $(1 \mathrm{~km})$ to overcome the imaging issue of very sparse data acquired for traveltime inversion along the Sinor-Valod profile (Fig. 1). The significant distortion happens in the basinal part having steep faults toward Sinor of the profile along with presence of thick column of sediments as top layer lying above the basalt, which generates severe noise in the data with amplitude change for different interfaces within the model and strong attenuation of seismic energy due to thick-column basalt layers (Fig. 13).

\section{Conclusions}

The present study mainly focuses the imaging of complex subsurface geological structures beneath highly heterogeneous and thick column of rugose basalt layers. These structures include very thin Mesozoic sediments that are prospective for hydrocarbon accumulations. The area was selected for this analysis because of the adequate amount of geological information available that helped to derive and constrain a model. This model was used to apply a tomographic imaging technique to obtain smooth and minimum-structure velocity model using first-arrival seismic data acquired along a 90-km-long profile (Behera and Sen 2014) in this basalt-covered Deccan Syneclise region (Fig. 1). We have adopted a raytrace inversion approach (Zelt and Smith 1992) by taking into consideration all the constraints of tomography and further picked the first-arrival traveltime data from all the nine wide-angle shots along the profile with proper classification of phases based on their respective layer velocities (Fig. 3) in a layer 
stripping manner (Behera et al. 2004). This helped to develop a ray-trace inversion velocity model along the profile (Fig. 4) that is well constrained, complex and realistic for generating synthetic seismic data with the help of elastic finite-difference full-wave modeling using staggered-grid scheme. These synthetic seismic data generated (Fig. 7) along this profile have been processed using migration techniques like Kirchhoff PSTM and PSDM to image very small-scale heterogeneities of the basalt interfaces and subtle hydrocarbon-bearing Mesozoic sediments hidden below the highly rugose thick basalts (Figs. 11, 13). It provides a very good insight about the fact that conventional seismic data acquisition using short spread and processing techniques fails to image below the thick basalts due to scattering, absorption, mode-conversions and multiples, hence leads to lower SNR of the seismic section. However, depth imaging using an approach involving elastic full-wave modeling helped to resolve complex subsurface geological structures with significant dip as well as highly heterogeneous and thick rugose basalts masking the hydrocarbonbearing Mesozoic sediments.

\section{Acknowledgements}

We thank Dr. V. M. Tiwari, Director, CSIR-NGRI, for according permission to publish the paper. We sincerely thank the anonymous reviewer for critical review with thought-provoking comments and Prof. Pierre Keating (Editor) for helpful suggestions to improve the quality of the paper. The elastic staggered-grid numerical computations are performed using the Tesseral codes of Tesseral Technologies Inc., Canada and ray-trace inversion codes RAYINVR of Prof. Colin A. Zelt, Rice University, Texas, USA are gratefully acknowledged. Funding from PSC0205 (LB) SHORE (CSIR) and GAP-52328 (LB) of SERC-DST are duly acknowledged. This work pertains to the scientific research contribution of CSIR-NGRI under MLP-6108-28 (LB).

Open Access This article is distributed under the terms of the Creative Commons Attribution 4.0 International License (http:// creativecommons.org/licenses/by/4.0/), which permits unrestricted use, distribution, and reproduction in any medium, provided you give appropriate credit to the original author(s) and the source, provide a link to the Creative Commons license, and indicate if changes were made.

\section{REFERENCES}

Allègre, C., Birck, J. L., Capmas, F., \& Courtillot, V. (1999). Age of the Deccan Traps using ${ }^{187} \mathrm{Re}-{ }^{187}$ Os systematic. Earth and Planetary Science Letters, 170, 199-204.

Beane, J. E., Turner, C. A., Hooper, P. R., Subbarao, K. V., \& Walsh, J. N. (1986). Stratigraphy, composition and form of the Deccan basalts, Western Ghats, India. Bulletin of Volcanology, 48, 61-83.

Behera, L., Sain, K., \& Reddy, P. R. (2004). Evidence of underplating from seismic and gravity studies in the Mahanadi Delta of eastern India and its tectonic significance. Journal of Geophysical Research, 109(B12311), 1-25.

Behera, L., \& Sen, M. K. (2014). Tomographic imaging of subbasalt Mesozoic sediments and shallow basement geometry for hydrocarbon potential below the Deccan Volcanic Province (DVP) of India. Geophysical Journal International, 199, 296-314.

Catchings, R. D., \& Mooney, W. D. (1988). Crustal structure of the Columbia Plateau: Evidence for continental rifting. Journal of Geophysical Research, 93, 459-474.

Červený, V., Molotkov, I. A., \& Pšenčík, I. (1977). Ray methods in seismology. Prague: University of Karlova.

Courtillot, V., Besse, J., Vandamme, D., Montigny, R., Jaegar, J. J., \& Capetta, H. (1986). Deccan flood basalts at the Cretaceous/ Tertiary boundary? Earth and Planetary Science Letters, 80, 361-374.

Courtillot, V., Féraud, G., Maluski, H., Vandamme, D., Moreau, M. G., \& Besse, J. (1988). Deccan flood basalts and the Cretaceous/ Tertiary boundary. Nature, 333, 843-846.

Cox, K. G. (1983). Deccan Traps and the Karoo: Stratigraphic implications of possible hot spot origins. IAVCEI programme and abstracts of XXIII IUGG general assembly. Hamburg, pp. 1-96.

Devey, C. W., \& Lightfoot, P. C. (1986). Volcanological and tectonic control of stratigraphy and structure in the western Deccan Traps. Bulletin of Volcanology, 48, 195-207.

Dixit, M. M., Tewari, H. C., \& Rao, C. V. (2010). Two-dimensional velocity model of the crust beneath the south Cambay basin, India from refraction and wide-angle reflection data. Geophysical Journal International, 181, 635-652.

Duncan, R. A., \& Pyle, D. G. (1988). Rapid eruption of the Deccan Traps at the Cretaceous/Tertiary boundary. Nature, 333, 841-843.

Firbas, P. (1987). Tomography from seismic profiles. In Nolet, G., \& Dordrecht, R. (Eds), Seismic tomography, pp. 189-202.

Fliedner, M. M., \& White, R. S. (2001). Seismic structure of basalt flows from surface seismic data, borehole measurements, and synthetic seismogram modeling. Geophysics, 66, 1925-1936.

Fliedner, M. M., \& White, R. S. (2003). Depth imaging of basalts in the Faeroe-Shetland basin. Geophysical Journal International, 152, 353-371.

Fruehn, J., Fliedner, M. M., \& White, R. S. (2001). Integrated wide-angle and near-vertical subbasalt study using large-aperture 
seismic data from the Faeroe-Shetland region. Geophysics, 66, 1340-1348.

Graves, R. W. (1996). Simulating seismic wave propagation in 3D elastic media using staggered-grid finite differences. Bulletin of the Seismological Society of America, 86, 1091-1106.

Huang, H., Spencer, C., \& Green, A. (1986). A method for the inversion of refraction and reflection travel times for laterally varying velocity structures. Bulletin of the Seismological Society of America, 76, 837-846.

Jarchow, C. M., Catchings, R. D., \& Lutter, W. J. (1994). Largeexplosive source, wide-recording aperture, seismic profiling on the Columbia Plateau, Washington. Geophysics, 59, 259-271.

Keller, G., Adatte, T., Gardin, S., Bartolini, A., \& Bajpai, S. (2008). Main Deccan volcanism phase ends near the K-T boundary: Evidence from the Krishna-Godavari Basin, SE India. Earth and Planetary Science Letters, 268, 293-311.

Kono, M. (1973). Geomagnetic polarity changes and the duration of volcanism in successive lava flows. Journal of Geophysical Research, 78, 5972-5982.

Levander, A. R. (1988). Fourth-order finite-difference P-SV seismograms. Geophysics, 53, 1425-1436.

Lutter, W. J., Nowack, R. L., \& Braile, L. W. (1990). Seismic imaging of upper crustal structure using travel times from the PASSCAL Ouachita experiment. Journal of Geophysical Research, 95, 4621-4631.

Mahoney, J. J., Natland, J. H., White, W. M., Poreda, R., Bloomer, S. H., Fisher, R. L., et al. (1989). Isotropic and geochemical provinces of the western Indian Ocean spreading centers. Journal of Geophysical Research, 94, 4033-4052.

McMechan, G. A., \& Mooney, W. D. (1980). Asymptotic ray theory and synthetic seismograms for laterally varying structures: Theory and application to the Imperial Valley, California. Bulletin of the Seismological Society of America, 70, 2021-2035.

Mitchell, C., \& Widdowson, M. (1991). A geological map of the southern Deccan Traps, India and its structural implications. Journal of Geological Society of London, 148, 495-505.

Morgan, W. J. (1972). Deep mantle convection plumes and plate tectonics. Bulletin of the American Association of Petroleum Geology, 56(1), 203-213.

Murty, A. S. N., Prasad, B. R., Rao, P. K., Raju, S., \& Sateesh, T. (2010). Delineation of subtrappean Mesozoic sediments in
Deccan Syneclise, India, using traveltime inversion of seismic refraction and wide-angle reflection data. Pure and Applied Geophysics, 167, 233-251.

Roy, T. K. (1991). Structural styles in southern Cambay basin, India and role of Narmada geofracture in formation of giant hydrocarbon accumulation. ONGC Bulletin, 27, 15-56.

Spence, G. D., Whittall, K. P., \& Clowes, R. M. (1984). Practical synthetic seismograms for laterally varying media calculated by asymptotic ray theory. Bulletin of the Seismological Society of America, 74, 1209-1223.

Tewari, H. C., Dixit, M. M., \& Murty, P. R. K. (1995). Use of traveltime skips in refraction analysis to delineate velocity inversion. Geophysical Prospecting, 43, 793-804.

Virieux, J. (1984). SH-wave propagation in heterogeneous media: Velocity-stress finite-difference method. Geophysics, 49, 1933-1957.

Virieux, J. (1986). P-SV wave propagation in heterogeneous media: Velocity-stress finite-difference method. Geophysics, 51, 889-901.

White, R. S., Smallwood, J. R., Fliedner, M. M., Boslaugh, B., Maresh, J., \& Fruehn, J. (2003). Imaging and regional distribution of basalt flows in the Faeroe-Shetland basin. Geophysical Prospecting, 51, 215-231.

Yang, L., Yan, H., \& Liu, H. (2014). Least squares staggered-grid finite-difference for elastic wave modeling. Exploration Geophysics, 45, 255-260.

Yilmaz, O. (1987). Seismic data processing. Tulsa: Society of Exploration Geophysicists.

Zelt, C. A. (1999). Modelling strategies and model assessment for wide-angle seismic traveltime data. Geophysical Journal International, 139, 183-204.

Zelt, C. A., \& Ellis, R. M. (1988). Practical and efficient ray tracing in two-dimensional media for rapid traveltime and amplitude forward modeling. Canadian Journal of Exploration Geophysics, 24, 16-31.

Zelt, C. A., \& Smith, R. B. (1992). Seismic traveltime inversion for 2-D crustal velocity structure. Geophysical Journal International, 108, 16-34.

Zelt, B. C., Talwani, M., \& Zelt, C. A. (1998). Prestack depth migration of dense wide-angle seismic data. Tectonophysics, 286, 193-208. 